\title{
DEA target setting using lexicographic and endogenous Directional Distance Function approaches
}

\author{
Sebastián Lozano ${ }^{\mathrm{a} \S}$ and Narges Soltani ${ }^{\mathrm{b}}$ \\ ${ }^{a}$ Dept. of Industrial Management, University of Seville, Spain \\ ${ }^{\mathrm{b}}$ Department of Mathematics, Kharazmi University, Tehran, Iran
}

ARTÍCULO PUBLICADO EN LA REVISTA

Journal of productivity Analysis (2018) 50, 55-70

doi: https://doi.org/10.1007/s11123-018-0534-x

\begin{abstract}
Directional Distance Function (DDF) is an approach often used in Data Envelopment Analysis (DEA) due to its clear interpretation and to the flexibility provided by the possibility of choosing the projection direction towards the efficient frontier. In this paper two new DDF approaches are considered. The first one uses an exogenous directional vector and a multi-stage methodology that at each step uses the projection along the input and output dimensions of the directional vector that can be improved. This lexicographic DDF approach also computes a directional efficiency score and a directional inefficiency indicator for each input and output variable. The second approach is a non-linear optimization model that endogenously determines the directional vector so that the smallest improvement required to reach the efficient frontier is computed.
\end{abstract}

Keywords: Data Envelopment Analysis; Directional Distance Function; multi-stage methodology; directional efficiency score; endogenous directional vector

$\S \quad$ Corresponding author:

Escuela Superior de Ingenieros

Camino de los Descubrimientos, s/n, 41092 Sevilla, Spain

(Phone: +34-954487208 E-mail: slozano@us.es) 


\section{Introduction}

Data envelopment analysis (DEA) is a non-parametric methodology that can be used to assess the relative efficiency of similar (i.e. homogeneous) organizational units commonly termed decision making units (DMUs) (Cooper et al. 2004, 2006). DEA only requires data about the input consumption and output production of the DMUs. From those data, and by applying the minimum extrapolating principle and some standard axioms (such as envelopment, free disposability and convexity), a Production Possibility Set (PPS) containing all the operating points that are deemed feasible can be inferred. The efficient frontier corresponds to the nondominated operating points of the PPS. DEA models aim at projecting each DMU onto the efficient frontier, computing a target operating point as well as an efficiency or inefficiency score. The inefficiency score is generally a measure of the distance from the DMU to the target operating point.

There are many different DEA models that differ in the orientation and metric considered. Thus, there are input-oriented, output-oriented and non-oriented DEA models, which, in turn, can use a radial, non-radial, hyperbolic or additive metric. One metric commonly used in DEA is the socalled Directional Distance Function (DDF), which considers a directional vector and tries to move in that direction until the border of the PPS is reached (Chambers et al. 1996). DDF DEA models have been used in many applications and are particularly suited when there are undesirable outputs (e.g. Lozano and Gutiérrez 2008, Lozano et al. 2013). The list of DEA applications that use a DDF approach is very long. One reason for the success of this type of DEA approach is its clear interpretation as a movement along a given direction. Another strong point of DDF is the possibility of choosing the directional vector. In fact, there are many different exogenous and endogenous ways of selecting such directional vectors (e.g. Färe et al. 2013, Zofío et al. 2013, Hampf and Krüger 2015, Daraio and Simar 2016). Wang et al. (2017) present a thorough survey of these methods.

In this paper two new DDF approaches are considered. The first one uses an exogenous directional vector. One disadvantage of DDF approaches with exogenous directional vectors is that the computed targets are generally weak efficient. This can be corrected using a slacks maximization phase II. That is done, for example, in Asmild and Pastor (2010) and in Pastor et al. (2016). In the latter, the phase II uses a conventional $l_{1}$ metric (i.e. additive) DEA model, 
while in the former the input and output slacks are normalized by the corresponding components of the range directional vector. In this paper a different approach to reach an efficient target is proposed, one that does not aim to maximize the sum of slacks but tries to keep using the information provided by the given directional vector. The proposed lexicographic approach carries out the projection of the DMU onto the efficient frontier in several steps, taking its inspiration from the multi-stage methodology that Coelli (1998) proposed for radial oriented DEA models. Cherchye and Van Puyenbroeck (2001) present an economic legitimation of this multi-stage methodology. Recently, Korhonen et al. (2018) have proposed a similar lexicographic approach for radial oriented DEA models. There are, however, some differences between the methods in Coelli (1998) and Korhonen et al. (2018). The latter consider nondiscretionary variables and the possibility of simultaneously changing any subset of the controllable inputs and output. They also compute inefficiency scores for each of the variables separately. As regards the identification of the input and output directions that can keep on improving in the next iteration, they use the optimal values of the corresponding input and output slacks, something which they admit can be problematic in the presence of degeneracy. The procedure in Coelli (1998) is more robust in this regard but requires solving a separate linear program for each of the input and output dimensions that can, in principle, be improved. The lexicographic DDF approach proposed in this paper can use any directional vector and therefore includes the lexicographic radial approaches of Coelli (1998) and Korhonen et al. (2018) as a special case. It also uses a different way of identifying the improvable input dimensions, based on a mixed-integer linear program (MILP) with a few binary variables, similar to the one used in Lozano and Calzada-Infante (2017). Finally, a way of aggregating the successive stepsizes carried out in each iteration is presented, which not only computes an inefficiency score for each variable but also determines the overall efficiency score for the DMU under evaluation.

The second DDF approach proposed in this paper uses an endogenously determined directional vector. This allows computing an efficient target in a single-step, thus dispensing with the multistage methodology used for the exogenous directional vector case. The basic idea behind the proposed endogenous DDF approach is to modify the largest improvement model of Färe et al (2013), or the units-invariant version of Hampf and Krüger (2015), so that instead of maximizing the improvement to be obtained, the smallest improvement required to reach the efficient frontier is computed. To implement this minimization instead of the conventional maximization 
approach, input and output multipliers are included in the model in order to determine a supporting hyperplane that passes through the target, thus ensuring its efficiency. The resulting optimization model is, however, non-linear.

The structure of this paper is the following. First, in Section 2, the basic DDF DEA model, the lexicographic radial approach and the largest improvement approach are reviewed. Sections 3 and 4 present the proposed lexicographic DDF and smallest improvement approaches, respectively. In Section 5 the proposed approach is illustrated with a small dataset. Finally, Section 6 summarizes and concludes.

\section{Review of relevant existing approaches}

\subsection{Notation and basic concepts}

Let

$\mathrm{j}=1,2, \ldots, \mathrm{n} \quad$ index on DMUs

$0 \quad$ index of a certain DMU whose efficiency is to be determined

$\mathrm{i}=1,2, \ldots, \mathrm{m} \quad$ index on inputs

$\mathrm{k}=1,2, \ldots, \mathrm{s} \quad$ index on outputs

$\mathrm{x}_{\mathrm{ij}} \quad$ amount of input $\mathrm{i}$ consumed by DMU $\mathrm{j}$

$\mathrm{y}_{\mathrm{kj}} \quad$ amount of output $\mathrm{k}$ produced by DMU j

If we assume Variable Returns to Scale (VRS), the corresponding PPS is formed by the convex linear combinations of the observed DMUs and the operating points that this convex hull dominate. Mathematically,

$$
\mathrm{T}^{\mathrm{VRS}}=\left\{(\mathrm{x}, \mathrm{y}) \mid \exists \lambda \geq 0 \quad \sum_{\mathrm{j}=1}^{\mathrm{n}} \lambda_{\mathrm{j}} \mathrm{x}_{\mathrm{ij}} \leq \mathrm{x}_{\mathrm{i}} \forall \mathrm{i} \quad \sum_{\mathrm{j}=1}^{\mathrm{n}} \lambda_{\mathrm{j}} \mathrm{y}_{\mathrm{kj}} \geq \mathrm{y}_{\mathrm{k}} \forall \mathrm{k} \quad \sum_{\mathrm{j}=1}^{\mathrm{n}} \lambda_{\mathrm{j}}=1\right\}
$$


All the DEA models that are formulated below to assess the efficiency use as decision variables these lambda variables (a.k.a. intensity variables) that represent the coefficients of the corresponding convex linear combination

$$
\left(\lambda_{1}, \lambda_{2}, \ldots \lambda_{\mathrm{n}}\right) \quad \text { intensity variables }
$$

By linearly combining the observed DMUs using these intensity variables, a feasible operating point can be computed. The operating points that are of interest are those that are efficient, i.e. non-dominated. Using the symbol $\wedge$ for the logical AND operation, the efficient frontier is:

$$
\mathrm{T}^{\mathrm{VRS}, \mathrm{eff}}=\left\{(\hat{\mathrm{x}}, \hat{\mathrm{y}}) \in \mathrm{T}^{\mathrm{VRS}} \mid\left[(\mathrm{x}, \mathrm{y}) \in \mathrm{T}^{\mathrm{VRS}}\right] \wedge[\mathrm{x} \leq \hat{\mathrm{x}}] \wedge[\mathrm{y} \geq \hat{\mathrm{y}}] \Rightarrow[\mathrm{x}=\hat{\mathrm{x}}] \wedge[\mathrm{y}=\hat{\mathrm{y}}]\right\}
$$

Assessing the technical efficiency of DMU 0 involves projecting onto an efficient target operating point that dominates it, i.e. finding an operating point in this subset $\left\{(\hat{\mathrm{x}}, \hat{\mathrm{y}}) \in \mathrm{T}^{\text {VRS, eff }} \mid \hat{\mathrm{x}} \leq \mathrm{x}_{0} \wedge \hat{\mathrm{y}} \geq \mathrm{y}_{0}\right\}$. This is where DEA models generally differ. Thus, some DEA models use an input orientation that gives priority to inputs reduction, while others use an output orientation that gives priority to outputs increase. There are also non-oriented DEA models that simultaneously aim at reducing inputs and increasing outputs. In any case, apart from the orientation, DEA models generally differ in the way the target operating point is determined. Some models are called radial because they try to keep the same input and output mix of DMU 0 (e.g. Banker et al. 1984), while others are non-radial and can lead to efficient targets with an input and output mix completely different from DMU 0 (e.g. Pastor et al. 1999). Furthermore, some DEA models project onto the most distant efficient target (e.g. Färe et al. 2013), while others aim at the closest efficient target (e.g. Aparicio 2016) and others compute a stepwise efficiency improvement path (e.g. Lozano and Villa 2005).

\subsection{Basic DDF approach}

DDF has a clear interpretation, which corresponds to DMU 0 moving along a direction given by a directional vector $g_{0}$ (Chambers et al. 1996). Wang et al. (2017) classify DDF approaches depending on whether the directional vector is determined endogenously, using a certain criterion, or not. Thus, for example, in Zofio et al. (2013) the directional vector is computed endogenously so that the target is allocative efficient while in Lee (2016) the directional vector is 
computed so that the benchmark is a Nash equilibrium in an imperfectly competitive market. In the conventional DDF approach, however, the directional vector is given, although it can depend on the specific DMU being projected and on the whole sample of DMUs (e.g. Silva Portela et al. 2004, Asmild and Pastor 2010, Daraio and Simar 2016). In any case, given the directional vector $\mathrm{g}_{0}=\left(\mathrm{g}^{\mathrm{x}}, \mathrm{g}^{\mathrm{y}}\right)$ the DDF model computes the maximum stepsize from $\left(\mathrm{x}_{0}, \mathrm{y}_{0}\right)$ along direction $\left(-g^{\mathrm{x}}, \mathrm{g}^{\mathrm{y}}\right)$.

$\operatorname{Max} \beta$

s.t.

$\sum_{\mathrm{j}} \lambda_{\mathrm{j}} \mathrm{x}_{\mathrm{ij}} \leq \mathrm{x}_{\mathrm{i} 0}-\beta \cdot \mathrm{g}_{\mathrm{i}}^{\mathrm{x}} \quad \forall \mathrm{i}$

$\sum_{\mathrm{j}} \lambda_{\mathrm{j}} \mathrm{y}_{\mathrm{kj}} \geq \mathrm{y}_{\mathrm{k} 0}+\beta \cdot \mathrm{g}_{\mathrm{k}}^{\mathrm{y}} \quad \forall \mathrm{k}$

$\sum_{\mathrm{j}} \lambda_{\mathrm{j}}=1$

$\lambda_{\mathrm{j}} \geq 0 \forall \mathrm{j} \quad \beta$ free

The above DDF DEA model does not necessarily project onto the efficient frontier. Thus, the corresponding target:

$$
\begin{aligned}
& \hat{\mathrm{x}}_{\mathrm{i}}=\mathrm{x}_{\mathrm{i} 0}-\beta^{*} \cdot \mathrm{g}_{\mathrm{i}}^{\mathrm{x}} \quad \forall \mathrm{i} \\
& \hat{\mathrm{y}}_{\mathrm{k}}=\mathrm{y}_{\mathrm{k} 0}+\beta^{*} \cdot \mathrm{g}_{\mathrm{k}}^{\mathrm{y}} \quad \forall \mathrm{k}
\end{aligned}
$$

can be just weak efficient. This, however, can be remedied by applying a phase two that exhausts any possible remaining input and output slacks. This phase two can also be incorporated into the DDF DEA model by introducing input and output slacks and using a very small constant $\rho>0$ 
$\operatorname{Max} \beta+\rho \cdot\left(\sum_{\mathrm{i}} \mathrm{s}_{\mathrm{i}}^{-}+\sum_{\mathrm{k}} \mathrm{s}_{\mathrm{k}}^{+}\right)$

s.t.

$\sum_{\mathrm{j}} \lambda_{\mathrm{j}} \mathrm{x}_{\mathrm{ij}}=\mathrm{x}_{\mathrm{i} 0}-\beta \cdot \mathrm{g}_{\mathrm{i}}^{\mathrm{x}}-\mathrm{s}_{\mathrm{i}}^{-} \cdot \mathrm{g}_{\mathrm{i}}^{\mathrm{x}} \quad \forall \mathrm{i}$

$\sum_{\mathrm{j}} \lambda_{\mathrm{j}} \mathrm{y}_{\mathrm{kj}}=\mathrm{y}_{\mathrm{k} 0}+\beta \cdot \mathrm{g}_{\mathrm{k}}^{\mathrm{y}}+\mathrm{s}_{\mathrm{k}}^{+} \cdot \mathrm{g}_{\mathrm{k}}^{\mathrm{y}} \quad \forall \mathrm{k}$

$\sum_{\mathrm{j}} \lambda_{\mathrm{j}}=1$

$\lambda_{\mathrm{j}} \geq 0 \forall \mathrm{j} \quad \beta$ free $\quad \mathrm{s}_{\mathrm{i}}^{-} \geq 0 \forall \mathrm{i} \quad \mathrm{s}_{\mathrm{k}}^{+} \geq 0 \forall \mathrm{k}$

Note that, in the above formulation, in order to keep the objective function dimensionless, we have used dimensionless input and output slacks.

\subsection{Lexicographic radial approach}

The lexicographic radial approach was termed multi-stage methodology by Coelli (1998), who proposed to use it for oriented DEA models in order to avoid the slacks maximization phase II. In radial DEA models, which is a special case of the DDF approach in which $\mathrm{g}_{0}=\left(\mathrm{x}_{0}, 0\right)$, $\mathrm{g}_{0}=\left(0, \mathrm{y}_{0}\right)$ or $\mathrm{g}_{0}=\left(\mathrm{x}_{0}, \mathrm{y}_{0}\right)$, in principle, unless a slacks maximization phase II is carried out, the computed target can be weak efficient, i.e. the target is not efficient but it can be improved only in some (not all) dimensions. That is because the movement along the radial direction may stop because one (or more) input or output dimensions cannot be further improved but that does not mean that there are no other dimensions in which further improvements are feasible. The idea behind the radial lexicographic approach is to exhaust those remaining slacks, not in the classical additive way but by keeping moving in a radial direction along the subspace spanned by the dimensions that can still be improved.

The main difference between Coelli (1998) and Korhonen et al. (2018) is that the former considers radial oriented DEA models (first with input orientation and later with output orientation or vice versa) while the latter considers the non-oriented case in which inputs and outputs are improved simultaneously. In order to mathematically formulate the lexicographic 
radial approach let us consider this latter case. Also, without loss of generality we will assume VRS. We will formulate the approach using our own notation. Thus, let $\mathrm{I}^{\mathrm{D}}$ and $\mathrm{I}^{\mathrm{ND}}$ (respectively, $\mathrm{O}^{\mathrm{D}}$ and $\mathrm{O}^{\mathrm{ND}}$ ) be the subsets of discretionary and non-discretionary inputs (respectively, outputs). The lexicographic radial approach defines, for each iteration $t$, the subsets of controllable inputs and outputs $\left(\mathrm{I}_{\mathrm{t}}^{-}\right.$and $\mathrm{O}_{\mathrm{t}}^{+}$, respectively) that can be improved from the previous iteration radial target $\left(\mathrm{x}^{\mathrm{t}-1}, \mathrm{y}^{\mathrm{t}-1}\right)$. Initially, $\mathrm{I}_{1}^{-}=\mathrm{I}^{\mathrm{D}}, \mathrm{O}_{1}^{+}=\mathrm{O}^{\mathrm{D}}$ and $\left(\mathrm{x}^{0}, \mathrm{y}^{0}\right)=\left(\mathrm{x}_{0}, \mathrm{y}_{0}\right)$.

The first step in the lexicographic radial approach involves solving:

$\operatorname{Max} \sigma_{0}+\rho \cdot\left(\sum_{\mathrm{i}} \mathrm{s}_{\mathrm{i}}^{-}+\sum_{\mathrm{k}} \mathrm{s}_{\mathrm{k}}^{+}\right)$

s.t.

$\sum_{\mathrm{j}} \lambda_{\mathrm{j}} \mathrm{x}_{\mathrm{ij}}=\mathrm{x}_{\mathrm{i} 0}-\sigma_{0} \cdot \mathrm{x}_{\mathrm{i} 0}-\mathrm{s}_{\mathrm{i}}^{-} \quad \forall \mathrm{i} \in \mathrm{I}^{\mathrm{D}}$

$\sum_{\mathrm{j}} \lambda_{\mathrm{j}} \mathrm{x}_{\mathrm{ij}} \leq \mathrm{x}_{\mathrm{i} 0} \quad \forall \mathrm{i} \in \mathrm{I}^{\mathrm{ND}}$

$\sum_{\mathrm{j}} \lambda_{\mathrm{j}} \mathrm{y}_{\mathrm{kj}}=\mathrm{y}_{\mathrm{k} 0}+\sigma_{0} \cdot \mathrm{y}_{\mathrm{k} 0}+\mathrm{s}_{\mathrm{k}}^{+} \quad \forall \mathrm{k} \in \mathrm{O}^{\mathrm{D}}$

$\sum_{\mathrm{j}} \lambda_{\mathrm{j}} \mathrm{y}_{\mathrm{kj}} \geq \mathrm{y}_{\mathrm{k} 0} \quad \forall \mathrm{k} \in \mathrm{O}^{\mathrm{ND}}$

$\sum_{j} \lambda_{j}=1$

$\lambda_{\mathrm{j}} \geq 0 \forall \mathrm{j} \quad \sigma_{0}$ free $\mathrm{s}_{\mathrm{i}}^{-} \geq 0 \forall \mathrm{i} \in \mathrm{I}^{\mathrm{D}} \quad \mathrm{s}_{\mathrm{k}}^{+} \geq 0 \forall \mathrm{k} \in \mathrm{O}^{\mathrm{D}}$

If the optimal solution of the above model has $\left(\mathrm{s}_{\mathrm{i}}^{-}\right)^{*}=0 \forall \mathrm{i} \in \mathrm{I}^{\mathrm{D}}$ and $\left(\mathrm{s}_{\mathrm{k}}^{+}\right)^{*}=0 \forall \mathrm{k} \in \mathrm{O}^{\mathrm{D}}$ then the radial target computed in this first step is already efficient and the procedure stops at 


$$
\begin{aligned}
& \mathrm{x}_{\mathrm{i}}^{1}=\mathrm{x}_{\mathrm{i} 0}-\sigma_{0}^{*} \cdot \mathrm{x}_{\mathrm{i} 0} \quad \forall \mathrm{i} \in \mathrm{I}^{\mathrm{D}} \\
& \mathrm{x}_{\mathrm{i}}^{1}=\mathrm{x}_{\mathrm{i} 0} \quad \forall \mathrm{i} \in \mathrm{I}^{\mathrm{ND}} \\
& \mathrm{y}_{\mathrm{k}}^{1}=\mathrm{y}_{\mathrm{k} 0}+\sigma_{0}^{*} \cdot \mathrm{y}_{\mathrm{k} 0} \quad \forall \mathrm{k} \in \mathrm{O}^{\mathrm{D}} \\
& \mathrm{y}_{\mathrm{k}}^{1}=\mathrm{y}_{\mathrm{k} 0} \quad \forall \mathrm{k} \in \mathrm{O}^{\mathrm{ND}}
\end{aligned}
$$

If that is not the case then the subsets of inputs and output dimensions that can be further improved are determined. Korhonen et al. (2018) do this based on the optimal values of the input and output slacks as follows:

$$
\mathrm{I}_{\mathrm{t}}^{-}=\left\{\mathrm{i} \in \mathrm{I}_{\mathrm{t}-1}^{-}:\left(\mathrm{s}_{\mathrm{i}}^{-}\right)^{*}>0\right\} \quad \mathrm{O}_{\mathrm{t}}^{+}=\left\{\mathrm{k} \in \mathrm{O}_{\mathrm{t}-1}^{+}:\left(\mathrm{s}_{\mathrm{k}}^{+}\right)^{*}>0\right\}
$$

Coelli (1998) uses a more robust approach that involves solving, for each input dimension $\mathrm{i}^{\prime} \in \mathrm{I}_{\mathrm{t}-1}^{-}$and output dimension $\mathrm{k}^{\prime} \in \mathrm{O}_{\mathrm{t}-1}^{+}$, a linear program that tries to improve that single dimension as much as possible.

$\operatorname{Min} \theta_{i^{\prime}}$

s.t.

$\sum_{j} \lambda_{j} x_{i^{\prime} j}=\theta_{i^{\prime}} x_{i^{\prime}}^{t-1}$

$\sum_{\mathrm{j}} \lambda_{\mathrm{j}} \mathrm{x}_{\mathrm{ij}} \leq \mathrm{x}_{\mathrm{i}}^{\mathrm{t}-1} \quad \forall \mathrm{i} \neq \mathrm{i}^{\prime}$

$\sum_{j} \lambda_{j} y_{k j} \geq y_{k}^{t-1} \quad \forall k$

$\sum_{j} \lambda_{j}=1$

$\lambda_{\mathrm{j}} \geq 0 \forall \mathrm{j}$
$\operatorname{Max} \gamma_{\mathrm{k}^{\prime}}$

s.t.

$\sum_{\mathrm{j}} \lambda_{\mathrm{j}} \mathrm{x}_{\mathrm{ij}} \leq \mathrm{x}_{\mathrm{i}}^{\mathrm{t}-1} \quad \forall \mathrm{i}$

$\sum_{j} \lambda_{j} y_{k^{\prime} j}=\gamma_{k^{\prime}} \cdot y_{k^{\prime}}^{t-1}$

$\sum_{\mathrm{j}} \lambda_{\mathrm{j}} \mathrm{y}_{\mathrm{kj}} \geq \mathrm{y}_{\mathrm{k}}^{\mathrm{t}-1} \quad \forall \mathrm{k} \neq \mathrm{k}^{\prime}$

$\sum_{j} \lambda_{j}=1$

$\lambda_{\mathrm{j}} \geq 0 \forall \mathrm{j}$

The subsets of inputs and outputs that can be improved in iteration $t$ are thus:

$$
\mathrm{I}_{\mathrm{t}}^{-}=\left\{\mathrm{i}^{\prime} \in \mathrm{I}_{\mathrm{t}-1}^{-}: \theta_{\mathrm{i}^{\prime}}^{*}<1\right\} \quad \mathrm{O}_{\mathrm{t}}^{+}=\left\{\mathrm{k}^{\prime} \in \mathrm{O}_{\mathrm{t}-1}^{+}: \gamma_{\mathrm{k}^{\prime}}^{*}>1\right\}
$$

In any case, the model to be solved for the next step $t$ is: 
$\operatorname{Max} \sigma_{\mathrm{t}-1}+\rho \cdot\left(\sum_{\mathrm{i}} \mathrm{s}_{\mathrm{i}}^{-}+\sum_{\mathrm{k}} \mathrm{s}_{\mathrm{k}}^{+}\right)$

s.t.

$\sum_{\mathrm{j}} \lambda_{\mathrm{j}} \mathrm{x}_{\mathrm{ij}}=\mathrm{x}_{\mathrm{i}}^{\mathrm{t}-1}-\sigma_{\mathrm{t}-1} \cdot \mathrm{x}_{\mathrm{i} 0}-\mathrm{s}_{\mathrm{i}}^{-} \quad \forall \mathrm{i} \in \mathrm{I}_{\mathrm{t}}^{-}$

$\sum_{\mathrm{j}} \lambda_{\mathrm{j}} \mathrm{x}_{\mathrm{ij}} \leq \mathrm{x}_{\mathrm{i}}^{\mathrm{t}-1} \quad \forall \mathrm{i} \notin \mathrm{I}_{\mathrm{t}}^{-}$

$\sum_{\mathrm{j}} \lambda_{\mathrm{j}} \mathrm{y}_{\mathrm{kj}}=\mathrm{y}_{\mathrm{k}}^{\mathrm{t}-1}+\sigma_{\mathrm{t}-1} \cdot \mathrm{y}_{\mathrm{k} 0}+\mathrm{s}_{\mathrm{k}}^{+} \quad \forall \mathrm{k} \in \mathrm{O}_{\mathrm{t}}^{+}$

$\sum_{\mathrm{j}} \lambda_{\mathrm{j}} \mathrm{y}_{\mathrm{kj}} \geq \mathrm{y}_{\mathrm{k}}^{\mathrm{t}-1} \quad \forall \mathrm{k} \notin \mathrm{O}_{\mathrm{t}}^{+}$

$\sum_{j} \lambda_{j}=1$

$\lambda_{\mathrm{j}} \geq 0 \forall \mathrm{j} \quad \sigma_{\mathrm{t}-1}$ free $\quad \mathrm{s}_{\mathrm{i}}^{-} \geq 0 \forall \mathrm{i} \in \mathrm{I}^{\mathrm{t}-} \quad \mathrm{s}_{\mathrm{k}}^{+} \geq 0 \forall \mathrm{k} \in \mathrm{O}^{\mathrm{t}+}$

which leads to the $\mathrm{t}$ step radial target:

$$
\begin{aligned}
& \mathrm{x}_{\mathrm{i}}^{\mathrm{t}}=\mathrm{x}_{\mathrm{i}}^{\mathrm{t}-1}-\sigma_{\mathrm{t}-1}^{*} \cdot \mathrm{x}_{\mathrm{i} 0} \quad \forall \mathrm{i} \in \mathrm{I}_{\mathrm{t}}^{-} \\
& \mathrm{x}_{\mathrm{i}}^{\mathrm{t}}=\mathrm{x}_{\mathrm{i}}^{\mathrm{t}-1} \quad \forall \mathrm{i} \notin \mathrm{I}_{\mathrm{t}}^{-} \\
& \mathrm{y}_{\mathrm{k}}^{\mathrm{t}}=\mathrm{y}_{\mathrm{k}}^{\mathrm{t}-1}+\sigma_{\mathrm{t}-1}^{*} \cdot \mathrm{y}_{\mathrm{k} 0} \quad \forall \mathrm{k} \in \mathrm{O}_{\mathrm{t}}^{+} \\
& \mathrm{y}_{\mathrm{k}}^{\mathrm{t}}=\mathrm{y}_{\mathrm{k}}^{\mathrm{t}-1} \quad \forall \mathrm{k} \notin \mathrm{O}_{\mathrm{t}}^{+}
\end{aligned}
$$

and to updated sets $\mathrm{I}_{\mathrm{t}+1}^{-}$and $\mathrm{O}_{\mathrm{t}+1}^{+}$. The procedure stops when $\mathrm{I}_{\mathrm{t}+1}^{-}=\mathrm{O}_{\mathrm{t}+1}^{+}=\varnothing$.

Korhonen et al. (2018) also define inefficiency scores for each controllable input and output dimension:

$$
\varphi_{\mathrm{i}}=\sum_{\left\{\mathrm{t}: \mathrm{i} \in \mathrm{I}_{\mathrm{t}}^{-}\right\}} \sigma_{\mathrm{t}-1}^{*} \quad \forall \mathrm{i} \in \mathrm{I}^{\mathrm{D}} \quad \hat{\varphi}_{\mathrm{k}}=\sum_{\left\{\mathrm{t}: \mathrm{k} \in \mathrm{O}_{\mathrm{t}}^{+}\right\}} \sigma_{\mathrm{t}-1}^{*} \quad \forall \mathrm{k} \in \mathrm{O}^{\mathrm{D}}
$$


These individual inefficiency scores are not aggregated, however, to compute an overall efficiency score for DMU 0, probably because the purpose of their paper is to identify the efficient target rather than efficiency estimation.

\subsection{Endogenous largest improvement DDF approach}

As mentioned in the introduction, the directional vector used in DDF can be exogenous (i.e. given a priori) or endogenously determined based on the own data (Wang et al. 2017). Among the latter methods one can use the approach proposed in Zofío et al. (2013), provided that the input and output unit prices are available. Otherwise, one can use the largest improvement model of Färe et al. (2013), in which the components of the directional vector are unknown variables to be determined using the following model

$\operatorname{Max} \beta$

s.t.

$\sum_{\mathrm{j}} \lambda_{\mathrm{j}} \mathrm{x}_{\mathrm{ij}} \leq \mathrm{x}_{\mathrm{i} 0}-\beta \cdot \mathrm{g}_{\mathrm{i}}^{\mathrm{x}} \quad \forall \mathrm{i}$

$\sum_{\mathrm{j}} \lambda_{\mathrm{j}} \mathrm{y}_{\mathrm{kj}} \geq \mathrm{y}_{\mathrm{k} 0}+\beta \cdot \mathrm{g}_{\mathrm{k}}^{\mathrm{y}} \quad \forall \mathrm{k}$

$\sum_{j} \lambda_{j}=1$

$\sum_{\mathrm{i}} \mathrm{g}_{\mathrm{i}}^{\mathrm{x}}+\sum_{\mathrm{k}} \mathrm{g}_{\mathrm{k}}^{\mathrm{y}}=1$

$\lambda_{\mathrm{j}} \geq 0 \forall \mathrm{j} \quad \beta \geq 0 \quad \mathrm{~g}_{\mathrm{i}}^{\mathrm{x}} \geq 0 \forall \mathrm{i} \quad \mathrm{g}_{\mathrm{k}}^{\mathrm{y}} \geq 0 \forall \mathrm{k}$

which can be linearized defining $\hat{\beta}_{\mathrm{i}}^{\mathrm{x}}=\beta \cdot \mathrm{g}_{\mathrm{i}}^{\mathrm{x}} \quad \forall \mathrm{i}$ and $\hat{\beta}_{\mathrm{k}}^{\mathrm{y}}=\beta \cdot \mathrm{g}_{\mathrm{k}}^{\mathrm{y}} \quad \forall \mathrm{k}$ which leads to 
$\operatorname{Max} \beta$

s.t.

$\sum_{\mathrm{j}} \lambda_{\mathrm{j}} \mathrm{x}_{\mathrm{ij}} \leq \mathrm{x}_{\mathrm{i} 0}-\hat{\beta}_{\mathrm{i}}^{\mathrm{x}} \quad \forall \mathrm{i}$

$\sum_{\mathrm{j}} \lambda_{\mathrm{j}} \mathrm{y}_{\mathrm{kj}} \geq \mathrm{y}_{\mathrm{k} 0}+\hat{\beta}_{\mathrm{k}}^{\mathrm{y}} \quad \forall \mathrm{k}$

$\sum_{j} \lambda_{j}=1$

$\sum_{\mathrm{i}} \hat{\beta}_{\mathrm{i}}^{\mathrm{x}}+\sum_{\mathrm{k}} \hat{\beta}_{\mathrm{k}}^{\mathrm{y}}=\beta$

$\lambda_{\mathrm{j}} \geq 0 \forall \mathrm{j} \quad \beta \geq 0 \quad \hat{\beta}_{\mathrm{i}}^{\mathrm{x}} \geq 0 \forall \mathrm{i} \quad \hat{\beta}_{\mathrm{k}}^{\mathrm{y}} \geq 0 \forall \mathrm{k}$

Note that although the first two sets of constraints are inequalities, they hold as equalities in any optimal solution. The optimal solution to the above model provides an inefficiency score $\beta^{*}$ as well as optimal, endogenously-computed direction vectors

$$
\left(\mathrm{g}_{\mathrm{i}}^{\mathrm{x}}\right)^{*}=\frac{\left(\hat{\beta}_{\mathrm{i}}^{\mathrm{x}}\right)^{*}}{\beta^{*}} \quad \forall \mathrm{i} \quad\left(\mathrm{g}_{\mathrm{k}}^{\mathrm{y}}\right)^{*}=\frac{\left(\hat{\beta}_{\mathrm{k}}^{\mathrm{y}}\right)^{*}}{\beta^{*}} \quad \forall \mathrm{k}
$$

For efficient units, $\beta^{*}=0$ and then any positive, normalized direction vector can be used, e.g. $\mathrm{g}_{\mathrm{i}}^{\mathrm{x}}=\frac{1}{\mathrm{~m}+\mathrm{s}} \quad \forall \mathrm{i},\left(\mathrm{g}_{\mathrm{k}}^{\mathrm{y}}\right)^{*}=\frac{1}{\mathrm{~m}+\mathrm{s}} \quad \forall \mathrm{k}$.

The model is called largest improvement because, contrary to the idea behind the closest efficient target approach, it looks for the directional vector that maximizes the stepsize $\beta$. The approach proposed in Section 4 can be called smallest improvement because what we propose is to find the directional vector that leads to the smallest stepsize $\beta$. Note, however, that just changing the objective function of model (15) from maximization to minimization would not work since the corresponding optimal solution would be $\beta^{*}=0$ even if DMU 0 is inefficient. 
Hampf and Krüger (2015) proposed the following units invariant version of the largest improvement model

$\operatorname{Max} \beta$

S.t.

$\sum_{\mathrm{j}} \lambda_{\mathrm{j}} \mathrm{x}_{\mathrm{ij}} \leq \mathrm{x}_{\mathrm{i} 0}-\beta \cdot \alpha_{\mathrm{i}}^{\mathrm{x}} \cdot \mathrm{x}_{\mathrm{i} 0} \quad \forall \mathrm{i}$

$\sum_{\mathrm{j}} \lambda_{\mathrm{j}} \mathrm{y}_{\mathrm{kj}} \geq \mathrm{y}_{\mathrm{k} 0}+\beta \cdot \alpha_{\mathrm{k}}^{\mathrm{y}} \cdot \mathrm{y}_{\mathrm{k} 0} \quad \forall \mathrm{k}$

$\sum_{j} \lambda_{j}=1$

$\sum_{\mathrm{i}} \alpha_{\mathrm{i}}^{\mathrm{x}}+\sum_{\mathrm{k}} \alpha_{\mathrm{k}}^{\mathrm{y}}=1$

$\lambda_{\mathrm{j}} \geq 0 \forall \mathrm{j} \quad \beta \geq 0 \quad \alpha_{\mathrm{i}}^{\mathrm{x}} \geq 0 \forall \mathrm{i} \quad \alpha_{\mathrm{k}}^{\mathrm{y}} \geq 0 \forall \mathrm{k}$

which can also be linearized defining $\hat{\hat{\beta}}_{\mathrm{i}}^{\mathrm{x}}=\beta \cdot \alpha_{\mathrm{i}}^{\mathrm{x}} \quad \forall \mathrm{i}$ and $\hat{\hat{\beta}}_{\mathrm{k}}^{\mathrm{y}}=\beta \cdot \alpha_{\mathrm{k}}^{\mathrm{y}} \quad \forall \mathrm{k}$

$\operatorname{Max} \beta$

s.t.

$\sum_{\mathrm{j}} \lambda_{\mathrm{j}} \mathrm{x}_{\mathrm{ij}} \leq \mathrm{x}_{\mathrm{i} 0}-\hat{\hat{\beta}}_{\mathrm{i}}^{\mathrm{x}} \cdot \mathrm{x}_{\mathrm{i} 0} \quad \forall \mathrm{i}$

$\sum_{\mathrm{j}} \lambda_{\mathrm{j}} \mathrm{y}_{\mathrm{kj}} \geq \mathrm{y}_{\mathrm{k} 0}+\hat{\hat{\beta}}_{\mathrm{k}}^{\mathrm{y}} \cdot \mathrm{y}_{\mathrm{k} 0} \quad \forall \mathrm{k}$

$\sum_{j} \lambda_{j}=1$

$\sum_{\mathrm{i}} \hat{\hat{\beta}}_{\mathrm{i}}^{\mathrm{x}}+\sum_{\mathrm{k}} \hat{\hat{\beta}}_{\mathrm{k}}^{\mathrm{y}}=\beta$

$\lambda_{\mathrm{j}} \geq 0 \forall \mathrm{j} \quad \beta \geq 0 \quad \hat{\hat{\beta}}_{\mathrm{i}}^{\mathrm{x}} \geq 0 \forall \mathrm{i} \quad \hat{\hat{\beta}}_{\mathrm{k}}^{\mathrm{y}} \geq 0 \forall \mathrm{k}$ 
As before, the two first set of constraints are binding at any optimal solution and the optimal solution of the above model provides an inefficiency score $\beta^{*}$ as well as an optimal, endogenously-computed direction vector

$$
\mathrm{g}_{\mathrm{i}}^{\mathrm{x}}=\frac{\left(\hat{\hat{\beta}}_{\mathrm{i}}^{\mathrm{x}}\right)^{*}}{\beta^{*}} \cdot \mathrm{x}_{\mathrm{i} 0} \quad \forall \mathrm{i} \quad \mathrm{g}_{\mathrm{k}}^{\mathrm{y}}=\frac{\left(\hat{\hat{\beta}}_{\mathrm{k}}^{\mathrm{y}}\right)^{*}}{\beta^{*}} \cdot \mathrm{y}_{\mathrm{k} 0} \quad \forall \mathrm{k}
$$

For efficient units, $\beta^{*}=0$ and any positive, normalized direction vector can be used, e.g. $\mathrm{g}_{\mathrm{i}}^{\mathrm{x}}=\frac{1}{\mathrm{~m}+\mathrm{s}} \cdot \mathrm{x}_{\mathrm{i} 0} \quad \forall \mathrm{i},\left(\mathrm{g}_{\mathrm{k}}^{\mathrm{y}}\right)^{*}=\frac{1}{\mathrm{~m}+\mathrm{s}} \cdot \mathrm{y}_{\mathrm{k} 0} \quad \forall \mathrm{k}$

\section{Proposed lexicographic DDF approach}

In the previous section the lexicographic radial approach was formulated in detail to facilitate appreciating the similarities and differences with respect to the proposed lexicographic DDF. To start with, we consider any directional vector $\mathrm{g}_{0}=\left(\mathrm{g}^{\mathrm{x}}, \mathrm{g}^{\mathrm{y}}\right)$, which means that the radial direction is a special case. Also, while the lexicographic radial approach starts by computing the first radial target and then determines the input and output dimensions, if any, that can still be further improved, we reverse this order and before computing the directional target we determine the input and output dimensions that can be improved. Thus, if there are not any controllable inputs and outputs that can be improved from DMU 0, we do not need to solve any DDF model because we can be certain that DMU 0 is efficient and the procedure stops.

In order to determine the controllable input and output dimensions that can be improved from the

initial operating point $\left(\mathrm{x}^{0}, \mathrm{y}^{0}\right)=\left(\mathrm{x}_{0}, \mathrm{y}_{0}\right)$ or from any subsequent directional target $\left(\mathrm{x}^{\mathrm{t}-1}, \mathrm{y}^{\mathrm{t}-1}\right)$, we propose to solve a MILP with a binary variable for each input and output dimension that could be improved in the previous iteration. The model is similar to the one used in Lozano and Calzada-Infante (2017). Let

$\mathrm{u}_{\mathrm{i}} \quad$ binary variable indicating whether or not input $\mathrm{i} \in \mathrm{I}_{\mathrm{t}-1}^{-}$can be reduced in iteration $\mathrm{t}$ 
$\mathrm{v}_{\mathrm{k}} \quad$ binary variable indicating whether or not output $\mathrm{k} \in \mathrm{O}_{\mathrm{t}-1}^{+}$can be increased in iteration $\mathrm{t}$

Note that, since we reverse the order in which the subsets of improvable input and output dimensions are determined, in our case, initially, $\mathrm{I}_{0}^{-}=\mathrm{I}^{\mathrm{D}}, \mathrm{O}_{0}^{+}=\mathrm{O}^{\mathrm{D}}$. The proposed approach uses the precision level (i.e. the number of decimal digits) of the corresponding input and output variables. Let us denote them as $\varepsilon_{\mathrm{i}}$ and $\hat{\varepsilon}_{\mathrm{k}}$, respectively. Thus, if a certain controllable input $\mathrm{i} \in \mathrm{I}^{\mathrm{D}}$ is measured with a precision of one or two decimal digits, then $\varepsilon_{\mathrm{i}}=0.1$ or $\varepsilon_{\mathrm{i}}=0.01$, respectively or if the variable does not consider rational numbers, then $\varepsilon_{i}=1$. In any case, the model to be solved to determine which controllable dimensions can be improved in iteration $\mathrm{t}$ is:

$\operatorname{Max} \sum_{\mathrm{i} \in \mathrm{I}_{\mathrm{t}-1}^{-}} \mathrm{u}_{\mathrm{i}}+\sum_{\mathrm{k} \in \mathrm{O}_{\mathrm{t}-1}^{+}} \mathrm{v}_{\mathrm{k}}$

s.t.

$\sum_{j=1}^{n} \lambda_{j} x_{i j}=x_{i}^{t-1}-\varepsilon_{i} \cdot u_{i} \quad \forall i \in I_{t-1}^{-}$

$\sum_{j=1}^{n} \lambda_{j} x_{i j} \leq x_{i}^{t-1} \quad \forall i \notin I_{t-1}^{-}$

$\sum_{j=1}^{n} \lambda_{j} y_{k j}=y_{k}^{t-1}+\hat{\varepsilon}_{k} \cdot v_{k} \quad \forall k \in O_{t-1}^{+}$

$\sum_{\mathrm{j}=1}^{\mathrm{n}} \lambda_{\mathrm{j}} \mathrm{y}_{\mathrm{kj}} \geq \mathrm{y}_{\mathrm{k}}^{\mathrm{t}-1} \quad \forall \mathrm{k} \notin \mathrm{O}_{\mathrm{t}-1}^{+}$

$\sum_{j=1}^{n} \lambda_{j}=1$

$\lambda_{\mathrm{j}} \geq 0 \forall \mathrm{j} \quad \mathrm{u}_{\mathrm{i}} \in\{0,1\} \forall \mathrm{i} \in \mathrm{I}_{\mathrm{t}-1}^{-} \quad \mathrm{v}_{\mathrm{k}} \in\{0,1\} \forall \mathrm{k} \in \mathrm{O}_{\mathrm{t}-1}^{+}$

The aim of model (20) is to detect all the input and output dimensions that can still be improved. Therefore, the parameters $\varepsilon_{\mathrm{i}}$ and $\hat{\varepsilon}_{\mathrm{k}}$ represent the minimum amount of change of those variables that can be counted as an improvement. Hence, as indicated in the text, their value is related to 
the precision level of the different variables. Thus, if a variable is measured with two decimal positions then a change in that variable smaller than 0.01 is not appreciable. In other words, only if the variable can be improved by at least 0.01 that input or output dimension can qualify as still able to improve.

Note also that model (20) allows determining all the dimensions that can be improved solving a single optimization model. The alternative is to do as in Coelli (1998) and solve model (9) for each controllable input and output dimension in the sets $\mathrm{I}_{\mathrm{t}-1}^{-}$and $\mathrm{O}_{\mathrm{t}-1}^{+}$.

The subsets of inputs and outputs that can be improved in iteration $t$ are thus:

$$
\mathrm{I}_{\mathrm{t}}^{-}=\left\{\mathrm{i} \in \mathrm{I}_{\mathrm{t}-1}^{-}: \mathrm{u}_{\mathrm{i}}^{*}=1\right\} \quad \mathrm{O}_{\mathrm{t}}^{+}=\left\{\mathrm{k} \in \mathrm{O}_{\mathrm{t}-1}^{+}: \mathrm{v}_{\mathrm{k}}^{*}=1\right\}
$$

If $\mathrm{I}_{\mathrm{t}}^{-}=\mathrm{O}_{\mathrm{t}}^{+}=\varnothing$ then the process stops as there are not any input or output dimensions that can be improved. Otherwise, we formulate and solve the DDF model for iteration t:

$\operatorname{Max} \beta_{\mathrm{t}}$

s.t.

$\sum_{j} \lambda_{j} x_{i j} \leq x_{i}^{t-1}-\beta_{t} \cdot g_{i}^{x} \quad \forall i \in I_{t}^{-}$

$\sum_{\mathrm{j}} \lambda_{\mathrm{j}} \mathrm{x}_{\mathrm{ij}} \leq \mathrm{x}_{\mathrm{i}}^{\mathrm{t}-1} \quad \forall \mathrm{i} \notin \mathrm{I}_{\mathrm{t}}^{-}$

$\sum_{\mathrm{j}} \lambda_{\mathrm{j}} \mathrm{y}_{\mathrm{kj}} \geq \mathrm{y}_{\mathrm{k}}^{\mathrm{t}-1}+\beta_{\mathrm{t}} \cdot \mathrm{g}_{\mathrm{k}}^{\mathrm{y}} \quad \forall \mathrm{k} \in \mathrm{O}_{\mathrm{t}}^{+}$

$\sum_{\mathrm{j}} \lambda_{\mathrm{j}} \mathrm{y}_{\mathrm{kj}} \geq \mathrm{y}_{\mathrm{k}}^{\mathrm{t}-1} \quad \forall \mathrm{k} \notin \mathrm{O}_{\mathrm{t}}^{+}$

$\sum_{j} \lambda_{j}=1$

$\lambda_{\mathrm{j}} \geq 0 \forall \mathrm{j} \quad \beta_{\mathrm{t}}$ free

which leads to the step $\mathrm{t}$ directional target: 


$$
\begin{aligned}
& \mathrm{x}_{\mathrm{i}}^{\mathrm{t}}= \begin{cases}\mathrm{x}_{\mathrm{i}}^{\mathrm{t}-1}-\beta_{\mathrm{t}}^{*} \cdot \mathrm{g}_{\mathrm{i}}^{\mathrm{x}} & \forall \mathrm{i} \in \mathrm{I}_{\mathrm{t}}^{-} \\
\mathrm{x}_{\mathrm{i}}^{\mathrm{t}-1} & \forall \mathrm{i} \notin \mathrm{I}_{\mathrm{t}}^{-}\end{cases} \\
& \mathrm{y}_{\mathrm{k}}^{\mathrm{t}}= \begin{cases}\mathrm{y}_{\mathrm{k}}^{\mathrm{t}-1}-\beta_{\mathrm{t}}^{*} \cdot \mathrm{g}_{\mathrm{k}}^{\mathrm{y}} & \forall \mathrm{k} \in \mathrm{O}_{\mathrm{t}}^{+} \\
\mathrm{y}_{\mathrm{k}}^{\mathrm{t}-1} & \forall \mathrm{k} \notin \mathrm{O}_{\mathrm{t}}^{+}\end{cases}
\end{aligned}
$$

As indicated above, the procedure stops if, after computing the iteration $\mathrm{T}$ directional target $\left(\mathrm{x}^{\mathrm{T}}, \mathrm{y}^{\mathrm{T}}\right)$, we solve model (20) for $\mathrm{t}=\mathrm{T}+1$ and the optimal objective function is zero, i.e. $\mathrm{u}_{\mathrm{i}}^{*}=0 \forall \mathrm{i} \in \mathrm{I}_{\mathrm{T}}^{-}$and $\mathrm{v}_{\mathrm{k}}^{*}=0 \forall \mathrm{k} \in \mathrm{O}_{\mathrm{T}}^{+}$. Therefore, $\left(\mathrm{x}^{\mathrm{T}}, \mathrm{y}^{\mathrm{T}}\right)$ is the final directional target computed by the lexicographic DDF approach. This final directional target can also be determined adding the corresponding improvements achieved in the successive iterations. Since each variable stops improving after a certain number of iterations, it is only necessary to add the step sizes of those iterations. This can be done using the indicator variables $\delta\left(\mathrm{i} \in \mathrm{I}_{\mathrm{t}}^{-}\right)$and $\delta\left(\mathrm{k} \in \mathrm{O}_{\mathrm{t}}^{+}\right)$that indicate whether a certain input $\mathrm{i}$ or output $\mathrm{k}$ was still able to improve in iteration $\mathrm{t}$ or, equivalently, the last iteration $\mathrm{T}(\mathrm{i})$ (respectively $\hat{\mathrm{T}}(\mathrm{k})$ ) in which a certain input $\mathrm{i}$ (respectively output $\mathrm{k}$ ) was able to improve. Mathematically,

$$
\begin{aligned}
& \delta\left(\mathrm{i} \in \mathrm{I}_{\mathrm{t}}^{-}\right)=\left\{\begin{array}{ll}
1 & \text { if } \mathrm{i} \in \mathrm{I}_{\mathrm{t}}^{-} \\
0 & \text { if } \mathrm{i} \notin \mathrm{I}_{\mathrm{t}}^{-}
\end{array} \quad \delta\left(\mathrm{k} \in \mathrm{O}_{\mathrm{t}}^{+}\right)= \begin{cases}1 & \text { if } \mathrm{k} \in \mathrm{O}_{\mathrm{t}}^{+} \\
0 & \text { if } \mathrm{k} \notin \mathrm{O}_{\mathrm{t}}^{+}\end{cases} \right. \\
& \mathrm{T}(\mathrm{i})=\max _{\mathrm{t}}\left\{\mathrm{t}: \mathrm{i} \in \mathrm{I}_{\mathrm{t}}^{-}\right\}
\end{aligned}
$$

Therefore, the final directional target can also be expressed as:

$$
\begin{aligned}
& \mathrm{x}_{\mathrm{i}}^{\mathrm{T}}=\mathrm{x}_{\mathrm{i} 0}-\mathrm{g}_{\mathrm{i}}^{\mathrm{x}} \cdot \sum_{\mathrm{t}=1}^{\mathrm{T}} \beta_{\mathrm{t}}^{*} \cdot \delta\left(\mathrm{i} \in \mathrm{I}_{\mathrm{t}}^{-}\right)=\mathrm{x}_{\mathrm{i} 0}-\mathrm{g}_{\mathrm{i}}^{\mathrm{x}} \cdot \sum_{\mathrm{t}=1}^{\mathrm{T}(\mathrm{i})} \beta_{\mathrm{t}}^{*} \\
& \mathrm{y}_{\mathrm{k}}^{\mathrm{T}}=\mathrm{y}_{\mathrm{k} 0}+\mathrm{g}_{\mathrm{k}}^{\mathrm{y}} \cdot \sum_{\mathrm{t}=1}^{\mathrm{T}} \beta_{\mathrm{t}}^{*} \cdot \delta\left(\mathrm{k} \in \mathrm{O}_{\mathrm{t}}^{+}\right)=\mathrm{y}_{\mathrm{k} 0}+\mathrm{g}_{\mathrm{k}}^{\mathrm{y}} \cdot \sum_{\mathrm{t}=1}^{\mathrm{T}(\mathrm{k})} \beta_{\mathrm{t}}^{*}
\end{aligned}
$$

Defining the directional inefficiency indicators: 


$$
\beta_{\mathrm{i}}^{\text {total }}=\sum_{\mathrm{t}=1}^{\mathrm{T}(\mathrm{i})} \beta_{\mathrm{t}}^{*} \forall \mathrm{i} \quad \hat{\beta}_{\mathrm{k}}^{\text {total }}=\sum_{\mathrm{t}=1}^{\hat{\mathrm{T}}(\mathrm{k})} \beta_{\mathrm{t}}^{*} \forall \mathrm{k}
$$

the efficiency score of DMU 0 along the given direction can be computed as:

$$
\eta_{0}=\frac{1-\frac{1}{\left|\mathrm{I}^{\mathrm{D}}\right|} \sum_{\mathrm{i} \in \mathrm{I}^{\mathrm{D}}} \frac{\beta_{\mathrm{i}}^{\mathrm{total}} \cdot \mathrm{g}_{\mathrm{i}}^{\mathrm{x}}}{\mathrm{x}_{\mathrm{i} 0}}}{1+\frac{1}{\left|\mathrm{O}^{\mathrm{D}}\right|} \sum_{\mathrm{k} \in \mathrm{O}^{\mathrm{D}}} \frac{\hat{\beta}_{\mathrm{k}}^{\mathrm{total}} \cdot \mathrm{g}_{\mathrm{k}}^{\mathrm{y}}}{\mathrm{y}_{\mathrm{k} 0}}}
$$

Note that the above expression is similar to the slacks-based measure of efficiency (SBM) (Tone 2001) in which the $\beta_{\mathrm{i}}^{\text {total }} \cdot \mathrm{g}_{\mathrm{i}}^{\mathrm{x}}$ and $\hat{\beta}_{\mathrm{k}}^{\text {total }} \cdot \mathrm{g}_{\mathrm{i}}^{\mathrm{x}}$ represent the total input and output slacks, respectively. It is clear that $0 \leq \eta_{0} \leq 1$. However, the SBM efficiency score of Tone (2001), which is equivalent to the Enhanced Russell Graph Measure (ERM) of Pastor et al. (1999), minimizes the ratio of the average input reduction to the average output expansion, without using any a priori projection direction, while the directional efficiency score $\eta_{0}$ is associated with the given direction vector $\mathrm{g}_{0}$. It is thus clear that the ERM/SBM efficiency score is always lower than (or at most equal to) the lexicographic DDF efficiency score $\eta_{0}$. Actually, the ERM/SBM corresponds to finding the minimum directional efficiency score among all the directional vectors $\left(\mathrm{g}^{\mathrm{x}}, \mathrm{g}^{\mathrm{y}}\right)$ with $\mathrm{g}_{\mathrm{i}}^{\mathrm{x}}>0 \forall \mathrm{i} \in \mathrm{I}^{\mathrm{D}}$ and $\mathrm{g}_{\mathrm{k}}^{\mathrm{y}}>0 \forall \mathrm{k} \in \mathrm{O}^{\mathrm{D}}$. Hence, since the ERM/SBM score coincides with the directional efficiency score for a certain direction, it can be considered as a special case of the directional efficiency score. In summary, the ERM/SBM efficiency score uses a non-radial approach whose direction projection is not defined a priori while the proposed approach projects along a given direction vector. Therefore, they are not directly comparable. In spite of this, as indicated above, because the proposed directional efficiency score has a functional form analogous to ERM/SBM, some interesting relationships between them can be derived. But this does not change the fundamental difference that one assumes a given directional vector while in the $\mathrm{ERM} / \mathrm{SBM}$ case the projection direction is free. 
The following result also holds:

Proposition 1: For any directional vector $\mathrm{g}_{0}=\left(\mathrm{g}^{\mathrm{x}}, \mathrm{g}^{\mathrm{y}}\right)$ with $\mathrm{g}_{\mathrm{i}}^{\mathrm{x}}>0 \forall \mathrm{i} \in \mathrm{I}^{\mathrm{D}}, \mathrm{g}_{\mathrm{k}}^{\mathrm{y}}>0 \forall \mathrm{k} \in \mathrm{O}^{\mathrm{D}}$, $\eta_{0}=1$ if and only if DMU 0 is efficient.

Proof:

$$
\begin{aligned}
& \eta_{0}=1 \quad \Leftrightarrow \quad \beta_{\mathrm{i}}^{\text {total }}=0 \quad \forall \mathrm{i} \in \mathrm{I}^{\mathrm{D}} \hat{\beta}_{\mathrm{k}}^{\text {total }}=0 \quad \forall \mathrm{k} \in \mathrm{O}^{\mathrm{D}} \Leftrightarrow \\
& \quad \Leftrightarrow \quad \mathrm{T}(\mathrm{i})=0 \quad \forall \mathrm{i} \in \mathrm{I}^{\mathrm{D}} \hat{\mathrm{T}}(\mathrm{k})=0 \quad \forall \mathrm{k} \in \mathrm{O}^{\mathrm{D}} \Leftrightarrow \mathrm{I}_{1}^{-}=\varnothing \mathrm{O}_{1}^{+}=\varnothing
\end{aligned}
$$

In summary, the basic difference between the proposed approach and the lexicographic radial approaches of Korhonen et al. (2018) and Coelli (1998) is that the latter carry out a radial projection, orientated in the case of Coelli (1998) and non-orientated in the case of Korhonen et al. (2018), while the proposed approach projects along a given direction vector. Hence the radial projection is a special case of the proposed approach. There are also algorithmic differences in the way the successive steps are carried out. These can be noted in the flowcharts of the three methods, shown in the appendix. Finally, the directional efficiency score (27) is another distinguishing feature of the proposed approach.

\section{Proposed smallest improvement approach}

The lexicographic DDF approach proposed in the previous section can be used when the directional vector is exogenous. Although it guarantees that the computed target is efficient, the multi-stage methodology used is somewhat complex, as it requires solving two models (one of them MILP) in each step. As one of the reviewers pointed out, it may be simpler to project onto the efficient frontier directly, by endogenously computing the appropriate directional vector. This can be done using, for example, the largest improvement models seen in Section 2.4. In this section, we propose a reformulation of those models so that instead of the largest improvement, which usually leads to a faraway target, the smallest improvement is sought, thus leading to a closest efficient target. 
To formulate the proposed model, we must do two modifications to models (15) and (18). One is to change the objective function from maximization to minimization and the other is to introduce input and output multipliers (plus intercept variable in the VRS case) and appropriate constraints so that a supporting hyperplane that passes through the computed target can be determined. Thus, letting $\mathrm{p}_{\mathrm{i}}$ (respectively, $\mathrm{q}_{\mathrm{k}}$ ) be the multiplier of input $\mathrm{i}$ (respectively, output $\mathrm{k}$ ), $\xi$ the intercept variable (equal to zero in the CRS case) and $\hat{x}_{i}$ and $\hat{y}_{k}$ the input and output targets, the corresponding constraints are

$$
\begin{aligned}
& \sum_{\mathrm{k}} \mathrm{q}_{\mathrm{k}} \mathrm{y}_{\mathrm{kj}}-\sum_{\mathrm{i}} \mathrm{p}_{\mathrm{i}} \mathrm{x}_{\mathrm{ij}}-\xi \leq 0 \quad \forall \mathrm{j} \\
& \sum_{\mathrm{k}} \mathrm{q}_{\mathrm{k}} \hat{\mathrm{y}}_{\mathrm{k}}-\sum_{\mathrm{i}} \mathrm{p}_{\mathrm{i}} \hat{\mathrm{x}}_{\mathrm{i}}-\xi=\left\{\begin{array}{l}
\sum_{\mathrm{k}} \mathrm{q}_{\mathrm{k}} \cdot\left(\mathrm{y}_{\mathrm{k} 0}+\hat{\beta}_{\mathrm{k}}^{\mathrm{y}}\right)-\sum_{\mathrm{i}} \mathrm{p}_{\mathrm{i}} \cdot\left(\mathrm{x}_{\mathrm{i} 0}-\hat{\beta}_{\mathrm{i}}^{\mathrm{x}}\right)-\xi=0 \quad \text { [for model (15)] } \\
\sum_{\mathrm{k}} \mathrm{q}_{\mathrm{k}} \cdot \mathrm{y}_{\mathrm{k} 0} \cdot\left(1+\hat{\hat{\beta}_{\mathrm{k}}^{\mathrm{y}}}\right)-\sum_{\mathrm{i}} \mathrm{p}_{\mathrm{i}} \cdot \mathrm{x}_{\mathrm{i} 0} \cdot\left(1-\hat{\hat{\beta}_{\mathrm{i}}^{\mathrm{x}}}\right)-\xi=0 \quad \text { [for model (18)] }
\end{array}\right. \\
& \mathrm{p}_{\mathrm{i}} \geq 1 \forall \mathrm{i} \quad \mathrm{q}_{\mathrm{k}} \geq 1 \forall \mathrm{k} \quad \xi \text { free } \\
& \sum_{\mathrm{i}} \mathrm{p}_{\mathrm{i}}+\sum_{\mathrm{k}} \mathrm{q}_{\mathrm{k}}=100
\end{aligned}
$$

The first set of constraints imposes that the hyperplane defined by $\mathrm{p}_{\mathrm{i}}, \mathrm{q}_{\mathrm{k}}$ and $\xi$ envelops the data. The second constraint guarantees that it is a supporting hyperplane, as it passes through the computed target. The third set of constraints guarantees the strong efficiency of the target and the last one is a normalization constraint that allows choosing among the alternative optimal multiplier vectors and that facilitates solving the non-linear optimization model.

Therefore, the smallest improvement version of model (15) is 
Min $\beta$

s.t.

$\hat{x}_{i}=\sum_{j} \lambda_{j} x_{i j}=x_{i 0}-\hat{\beta}_{i}^{x} \quad \forall i$

$\hat{\mathrm{y}}_{\mathrm{k}}=\sum_{\mathrm{j}} \lambda_{\mathrm{j}} \mathrm{y}_{\mathrm{kj}}=\mathrm{y}_{\mathrm{k} 0}+\hat{\beta}_{\mathrm{k}}^{\mathrm{y}} \quad \forall \mathrm{k}$

$\sum_{j} \lambda_{j}=1$

$\sum_{\mathrm{i}} \hat{\beta}_{\mathrm{i}}^{\mathrm{x}}+\sum_{\mathrm{k}} \hat{\beta}_{\mathrm{k}}^{\mathrm{y}}=\beta$

$\sum_{\mathrm{k}} \mathrm{q}_{\mathrm{k}} \mathrm{y}_{\mathrm{kj}}-\sum_{\mathrm{i}} \mathrm{p}_{\mathrm{i}} \mathrm{x}_{\mathrm{ij}}-\xi \leq 0 \quad \forall \mathrm{j}$

$\sum_{\mathrm{k}} \mathrm{q}_{\mathrm{k}} \mathrm{y}_{\mathrm{k} 0}-\sum_{\mathrm{i}} \mathrm{p}_{\mathrm{i}} \mathrm{x}_{\mathrm{i} 0}-\xi=-\left[\sum_{\mathrm{i}} \mathrm{p}_{\mathrm{i}} \hat{\beta}_{\mathrm{i}}^{\mathrm{x}}+\sum_{\mathrm{k}} \mathrm{q}_{\mathrm{k}} \hat{\beta}_{\mathrm{k}}^{\mathrm{y}}\right]$

$\mathrm{p}_{\mathrm{i}} \geq 1 \forall \mathrm{i} \quad \mathrm{q}_{\mathrm{k}} \geq 1 \forall \mathrm{k} \quad \xi$ free

$\sum_{\mathrm{i}} \mathrm{p}_{\mathrm{i}}+\sum_{\mathrm{k}} \mathrm{q}_{\mathrm{k}}=100$

$\lambda_{\mathrm{j}} \geq 0 \forall \mathrm{j} \quad \beta \geq 0 \quad \hat{\beta}_{\mathrm{i}}^{\mathrm{x}} \geq 0 \forall \mathrm{i} \quad \hat{\beta}_{\mathrm{k}}^{\mathrm{y}} \geq 0 \forall \mathrm{k}$

and that of model (18) is 
Min $\beta$

s.t.

$\hat{\mathrm{x}}_{\mathrm{i}}=\sum_{\mathrm{j}} \lambda_{\mathrm{j}} \mathrm{x}_{\mathrm{ij}}=\mathrm{x}_{\mathrm{i} 0}-\hat{\hat{\beta}}_{\mathrm{i}}^{\mathrm{x}} \cdot \mathrm{x}_{\mathrm{i} 0} \quad \forall \mathrm{i}$

$\hat{\mathrm{y}}_{\mathrm{k}}=\sum_{\mathrm{j}} \lambda_{\mathrm{j}} \mathrm{y}_{\mathrm{kj}}=\mathrm{y}_{\mathrm{k} 0}+\hat{\hat{\beta}}_{\mathrm{k}}^{\mathrm{y}} \cdot \mathrm{y}_{\mathrm{k} 0} \quad \forall \mathrm{k}$

$\sum_{j} \lambda_{j}=1$

$\sum_{\mathrm{i}} \hat{\hat{\beta}}_{\mathrm{i}}^{\mathrm{x}}+\sum_{\mathrm{k}} \hat{\hat{\beta}}_{\mathrm{k}}^{\mathrm{y}}=\beta$

$\sum_{\mathrm{k}} \mathrm{q}_{\mathrm{k}} \mathrm{y}_{\mathrm{kj}}-\sum_{\mathrm{i}} \mathrm{p}_{\mathrm{i}} \mathrm{x}_{\mathrm{ij}}-\xi \leq 0 \quad \forall \mathrm{j}$

$\sum_{\mathrm{k}} \mathrm{q}_{\mathrm{k}} \mathrm{y}_{\mathrm{k} 0}-\sum_{\mathrm{i}} \mathrm{p}_{\mathrm{i}} \mathrm{x}_{\mathrm{i} 0}-\xi=-\left[\sum_{\mathrm{i}} \mathrm{p}_{\mathrm{i}} \hat{\hat{\beta}}_{\mathrm{i}}^{\mathrm{x}} \mathrm{x}_{\mathrm{i} 0}+\sum_{\mathrm{k}} \mathrm{q}_{\mathrm{k}} \hat{\hat{\beta}}_{\mathrm{k}}^{\mathrm{y}} \mathrm{y}_{\mathrm{k} 0}\right]$

$\mathrm{p}_{\mathrm{i}} \geq 1 \forall \mathrm{i} \quad \mathrm{q}_{\mathrm{k}} \geq 1 \forall \mathrm{k} \quad \xi$ free

$\sum_{\mathrm{i}} \mathrm{p}_{\mathrm{i}}+\sum_{\mathrm{k}} \mathrm{q}_{\mathrm{k}}=100$

$\lambda_{\mathrm{j}} \geq 0 \forall \mathrm{j} \quad \beta \geq 0 \quad \hat{\hat{\beta}}_{\mathrm{i}}^{\mathrm{x}} \geq 0 \forall \mathrm{i} \quad \hat{\hat{\beta}}_{\mathrm{k}}^{\mathrm{y}} \geq 0 \forall \mathrm{k}$

Both endogenous smallest improvement DDF models are non-linear. Model (30) has the advantage of being units-invariant.

\section{Illustration}

In order to illustrate the proposed approaches, consider the two-input, single-output dataset shown in Table 1. All the variables are assumed to be controllable. There are 10 DMUs of which six (namely DMUs A to F) are efficient. The other four are inefficient with two of them (namely, DMUs I and J) weak efficient. 
Table 2 shows the results of the application of the lexicographic DDF approach to the inefficient DMUs G and H. In each case, three different scenarios (i.e. three different directional vectors) are considered. The different steps carried out in each scenario and the successive operating points computed can be seen in Figure 1. Note that, since the total number of variables is three, that is also the maximum number of steps that may be required to reach the efficient frontier. However, the number of steps that are required actually is often lower than the maximum. Thus, for the three directional vectors considered for DMU G, in one case the target of the first iteration (which in this case coincides with the conventional DDF target) is already efficient (i.e. $\mathrm{T}=1$ ). In the other two cases, a second step is required (i.e. $\mathrm{T}=2$ ). For DMU $\mathrm{H}$, of the three directional vectors considered, in one case two steps of the lexicographic DDF approach are needed while in the other two scenarios three steps are required (i.e. T=3). In any case, for each directional vector, the inefficiency indicator for each input and output are shown together, with the efficiency score of the DMU computed along that direction.

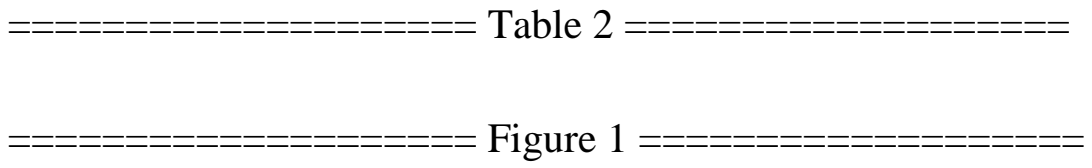

Table 3 and Figure 2 show the results of the application of the lexicographic DDF approach to the two weak efficient DMUs. In the case of DMU J, solving model (20) in the first iteration detects that there is one dimension (namely, $\mathrm{x}_{1}$ ) that cannot be improved. The conventional DDF model would determine $\beta^{*}=0$ when trying to advance along $\mathrm{g}_{\mathrm{J}}$. In our case, since we remove $\mathrm{x}_{1}$ from the set $\mathrm{I}_{1}^{-}$, we can determine a positive stepsize along the direction defined by the other two directional vector components. In any case, for this DMU, at most two steps have to be carried out. Actually, for the three directional vectors considered, two steps were required. Something similar happens when projecting the weak efficient DMU I only, in this case, initially there are two dimensions (namely, $\mathrm{x}_{1}$ and $\mathrm{y}$ ) that cannot be improved. That is detected by model (20) in the first iteration so that they are removed from $\mathrm{I}_{1}^{-}$and $\mathrm{O}_{1}^{+}$, respectively. This means that, for this DMU, independently of the directional vector, only one step is required to reach the efficient frontier and the movement is always along the $\mathrm{x}_{2}$ axis. 


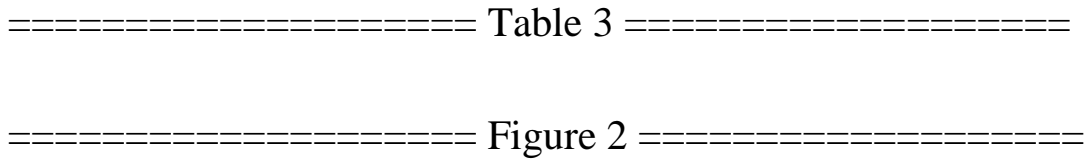

Table 4 and 5 show the results of the smallest improvement DEA models (29) and (30), respectively, for this dataset. The corresponding non-linear optimization models have been solved in GAMS using COUENNE solver. The computing times require are shown in the last column. For the efficient DMUs the optimal objective function is $\beta^{*}=0$. For the inefficient DMUs, the variables $\left(\hat{\beta}_{1}^{\mathrm{x}}\right)^{*},\left(\hat{\beta}_{2}^{\mathrm{x}}\right)^{*}$ and $\left(\hat{\beta}^{\mathrm{y}}\right)^{*}$ of model (29) indicate the corresponding improvements along the two inputs and the output dimension, respectively. In the case of model (30) the corresponding improvements are $\mathrm{x}_{10} \cdot\left(\hat{\hat{\beta}}_{1}^{\mathrm{x}}\right)^{*}, \mathrm{x}_{20} \cdot\left(\hat{\hat{\beta}}_{2}^{\mathrm{x}}\right)^{*}$ and $\mathrm{y}_{0} \cdot\left(\hat{\hat{\beta}}^{\mathrm{y}}\right)^{*}$. Note that, although that does not have to occur in general, for this small dataset the targets computed by both models coincide. All these targets lie on the efficient frontier. In particular, for DMU $\mathbf{J}$ the target coincides with one of the DMUs, namely DMU E.

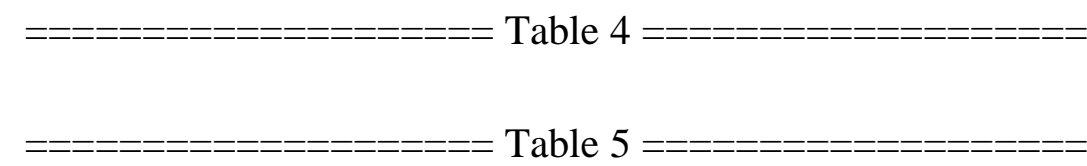

For the sake of comparison, the results of the largest improvement DDF models (15) and (18) are shown in Table 6. Note that, for the inefficient DMUs, the optimal $\beta^{*}$ value for the largest improvement models (15) and (18) are larger than for smallest improvement models (29) and (30). Again, although this does not occur in general, the targets computed by the two largest improvement models coincide. In particular, the target of both DMU G and H coincides with DMU D and the target computed for DMU J coincides with DMU E. From Figure 1 it can be seen that, within the region that dominates DMU G, DMU D is farthest from it and the same happens in the case of DMU H. In the case of DMU J it happens that there is only one efficient operating point in the region that dominates it and that is DMU E (see Figure 2). Hence, that is the target computed by both the largest and the smallest improvement models. That happens also with DMU I. This can be seen in Figure 3, which shows the projections of the four inefficient DMUs computed by the largest and smallest improvement DDF approaches. 


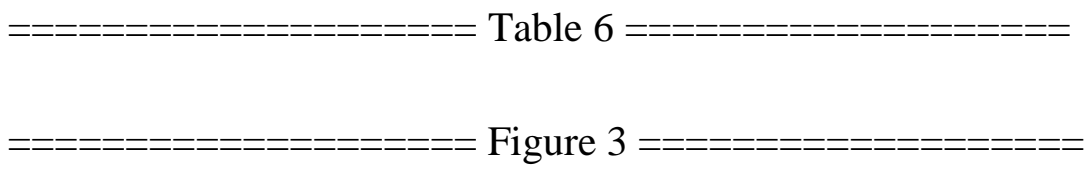

\section{Conclusions}

In this paper, two new DDF approaches are proposed. One of them can be used when the directional vector is exogenously given but does not use a slacks-maximizing phase to overcome the weak efficient of the target computed by the conventional DDF approach. Instead, it uses a lexicographic approach that follows the given directional vector along all the input and output dimensions that are susceptible to improvement at each step. This type of multi-stage methodology has been used before, for radial DEA models, by Coelli (1998) and, more recently, by Korhonen et al. (2018). In our case, in each step of the proposed lexicographic DDF approach, two different DEA models are used. First, a MILP model that identifies the input and output dimensions that can be improved is solved, followed by a DDF DEA model that moves along the projection of the given directional distance along those input and output dimensions. The lexicographic DDF approach has a clear graphical interpretation and requires a limited number of steps. Moreover, it contains the lexicographic radial approach as a special case and can be used also with non-discretionary variables, undesirable outputs and integer variables. A directional efficiency score as well as directional inefficiency indicators for each input and output variable are computed. Although the directional efficiency score has a functional form analogous to that of ERM/SBM efficiency score they are fundamentally different. Thus, while $\mathrm{ERM} / \mathrm{SBM}$ is free to choose the projection direction and chooses the one that minimizes the corresponding efficiency score, the proposed lexicographic DDF approach computes the directional efficiency score associated with the given directional vector.

An endogenous direction DDF approach has been proposed also. This does not require an exogenous direction and can compute an efficient target in a single step. The proposed endogenous DDF approach is based on the largest improvement models of Färe et al. (2013) and Hampf and Krüger (2015) but instead of considering the direction that maximizes the corresponding DDF, a smallest improvement criterion is used with the aim of computing a 
closest efficient target. The corresponding minimization model includes input and output multipliers that define a supporting hyperplane that passes through the computed efficient target. Although a units-invariant version can be used, the proposed smallest improvement approach requires, in any case, solving a non-linear optimization model.

Possible continuations of this research include extending the approach to centralized DEA and network DEA contexts. Developing an extension for interval and fuzzy data would also be interesting.

\section{Acknowledgements}

This research was carried out with the financial support of the Spanish Ministry of Economy, Industry and Competitiveness, DPI2017-85343-P. Narges Soltani acknowledges the support of a grant from the Ministry of Science, Research and Technology of the Islamic Republic of Iran. We would also like to thank the reviewers for their constructive and helpful remarks and suggestions.

\section{Appendix}

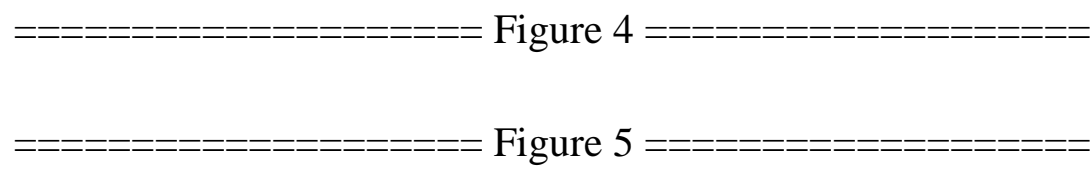

\section{References}

Aparicio, J., "A survey on measuring efficiency through the determination of the least distance in data envelopment analysis", Journal of Centrum Cathedra, 9, 2 (2016) 143-167

Asmild, M. and Pastor, J.T., "Slack free MEA and RDM with comprehensive efficiency measures", Omega, 38 (2010) 475-483

Banker, R.D., Charnes, A. and Cooper, W.W., "Some models for estimating technical and scale inefficiencies in data envelopment analysis”, Management Science, 30, 9 (1984) 1078-1092

Chambers, R.G., Chung, Y. and Färe, R., "Benefit and Distance Functions", Journal of Economic Theory, 70 (1996) 407-419 
Cherchye, L. and Van Puyenbroeck, T., "A comment on multi-stage DEA methodology", Operations Research Letters, 28 (2001) 93-98

Coelli, T., "A multi-stage methodology for the solution of orientated DEA models", Operations Research Letters, 23 (1998) 143-149

Cooper, W.W., Seiford, L.M. and Zhu, J., Handbook on Data Envelopment Analysis, Springer, New York, 2004

Cooper, W.W., Seiford, L.M. and Tone, K., Data Envelopment Analysis: A Comprehensive Text with Models, Applications, References and DEA-Solver Software, 2nd edition, Springer, New York, 2006

Daraio, C. and Simar, L., "Efficiency and benchmarking with directional distances: a data-driven approach", Journal of the Operational Research Society, 67 (2016) 928-944

Färe, R., Grosskopf, S. and Wittaker, G., "Directional output distance functions: Endogenous constraints based on exogenous normalization constraints", Journal of Productivity Analysis, 40 (2013) 267-269

Hampf, B. and Krüger, J. J., "Optimal directions for directional distance functions: An exploration of potential reductions of greenhouse gases", American Journal of Agricultural Economics, 97, 3 (2015) 920-938

Korhonen, P.J., Dehnokhalaji, A. and Nasrabadi, N., “A lexicographic radial projection onto the efficient frontier in Data Envelopment Analysis", European Journal of Operational Research, 265 (2018) 1005-1012

Lee, C.Y., "Nash-Profit Efficiency: A Measure of Changes in Market Structures", European Journal of Operational Research, 255, 2 (2016) 659-663

Lozano, S. and Villa, G., "Determining a sequence of targets in DEA", Journal of the Operational Research Society, 56 (2005) 1439-1447

Lozano, S. and Gutiérrez, E., "Non-parametric frontier approach to modelling the relationships among population, GDP, energy consumption and CO2 emissions”, Ecological Economics, 66 (2008) 687-699 
Lozano, S., Gutiérrez, E. and Moreno, P., "Network DEA approach to airports performance assessment considering undesirable outputs", Applied Mathematical Modelling, 37 (2013) 16651676

Lozano, S. and Calzada-Infante, L., "Computing gradient-based stepwise benchmarking paths", Omega, (2017) (doi: 10.1016/j.omega.2017.11.002)

Pastor, J.T., Ruiz, J.L. and Sirvent, I., "An enhanced DEA Russell graph efficiency measure", European Journal of Operational Research, 115 (1999) 596-607

Pastor, J.T., Aparicio, J., Alcaraz, J., Vidal, F. and Pastor, D., "The Reverse Directional Distance Function", in Advances in Efficiency and Productivity, J. Aparicio et al. (eds.), International Series in Operations Research \& Management Science, vol. 249 (2016) 15-55

Silva Portela, M.C.A., Thanassoulis, E., Simpson, G., "Negative data in DEA: a directional distance function approach applied to bank branches", Journal of the Operational Research Society, 55, 10 (2004) 1111-1121

Tone, K., "A slacks-based measure of efficiency in data envelopment analysis", European Journal of Operational Research, 130, 3 (2001) 498-509

Wang, K., Xian, Y., Lee, C.Y., Wei, Y.M. and Huang, Z., "On selecting directions for directional distance functions in a non-parametric framework: a review", Annals of Operations Research, (2017) (doi: 10.1007/s10479-017-2423-5)

Zofio, J.L., Pastor, J.T. and Aparicio, J., "The directional profit efficiency measure: on why profit inefficiency is either technical or allocative", Journal of Productivity Analysis, 40 (2013) $257-266$ 


\section{List of figure and table captions}

Table 1. Illustration dataset

Table 2. Results of Lexicographic DDF projection of inefficient DMUs $G$ and $H$ for three different directional vectors

Table 3. Results of Lexicographic DDF projection of weak efficient DMUs I and $\mathbf{J}$ for three different directional vectors

Table 4. Results of smallest improvement DDF model (29)

Table 5. Results of smallest improvement DDF model (30)

Table 6. Results of largest improvement DDF models (15) and (18)

Figure 1. Lexicographic DDF projection of inefficient DMUs $G$ and $H$ for three different directional vectors (the coordinates of the points are shown with one decimal digit; the exact values are shown in Table 2)

Figure 2. Lexicographic DDF projection of weak efficient DMUs I and $\mathbf{J}$ for three different directional vectors (the coordinates of the points are shown with one decimal digit; the exact values are shown in Table 3)

Figure 3. Largest and smallest improvement projections of inefficient DMUs

Figure 4. Flowchart of the lexicographic radial approaches of Korhonen et al. (2018) and Coelli (1998)

Figure 5. Flowchart of the proposed lexicographic DDF approach 
Table 1. Illustration dataset

\begin{tabular}{|c|r|r|r|}
\hline DMU & \multicolumn{1}{|c|}{$x_{1}$} & $x_{2}$ & $y$ \\
\hline A & 12 & 30 & 90 \\
\hline B & 25 & 9 & 51 \\
\hline C & 43 & 11 & 70 \\
\hline D & 20 & 19 & 98 \\
\hline E & 2 & 22 & 43 \\
\hline F & 5 & 7 & 13 \\
\hline G & 30 & 49 & 40 \\
\hline H & 40 & 45 & 30 \\
\hline I & 5.62 & 40 & 60.01 \\
\hline J & 2 & 35 & 22 \\
\hline
\end{tabular}


Table 2. Results of Lexicographic DDF projection of inefficient DMUs G and $\mathrm{H}$ for three different directional vectors

\begin{tabular}{|c|c|c|c|c|c|c|c|c|c|c|c|c|c|c|c|c|c|c|c|c|}
\hline \multicolumn{21}{|c|}{ DMU G } \\
\hline \multicolumn{7}{|c|}{$\mathrm{g}_{\mathrm{G}}=(1,5,1)$} & \multicolumn{7}{|c|}{$\mathrm{g}_{\mathrm{G}}=(5,1,1)$} & \multicolumn{7}{|c|}{$\mathrm{g}_{\mathrm{G}}=(1,1,5)$} \\
\hline $\mathrm{t}$ & $\mathrm{I}_{\mathrm{t}}^{-}$ & $\mathrm{O}_{\mathrm{t}}^{+}$ & $\beta_{\mathrm{t}}$ & $x_{1}^{t}$ & $x_{2}^{t}$ & $y_{t}$ & $\mathrm{t}$ & $\mathrm{I}_{\mathrm{t}}^{-}$ & $\mathrm{O}_{\mathrm{t}}^{+}$ & $\beta_{\mathrm{t}}$ & $\mathrm{x}_{1}^{\mathrm{t}}$ & $x_{2}^{t}$ & $\mathrm{y}_{\mathrm{t}}$ & $\mathrm{t}$ & $\mathrm{I}_{\mathrm{t}}^{-}$ & $\mathrm{O}_{\mathrm{t}}^{+}$ & $\beta_{\mathrm{t}}$ & $x_{1}^{t}$ & $x_{2}^{t}$ & $\mathrm{y}_{\mathrm{t}}$ \\
\hline 0 & $\mathrm{x}_{1}, \mathrm{x}_{2}$ & $\mathrm{y}$ & - & 30.00 & 49.00 & 40.00 & 0 & $\mathrm{x}_{1}, \mathrm{x}_{2}$ & $\mathrm{y}$ & - & 30.00 & 49.00 & 40.00 & 0 & $\mathrm{x}_{1}, \mathrm{x}_{2}$ & $\mathrm{y}$ & - & 30.00 & 49.00 & 40.00 \\
\hline 1 & $\mathrm{x}_{1}, \mathrm{x}_{2}$ & $\mathrm{y}$ & 7.96 & 22.04 & 9.18 & 47.96 & 1 & $\mathrm{x}_{1}, \mathrm{x}_{2}$ & $\mathrm{y}$ & 5.49 & 2.53 & 43.51 & 46.49 & 1 & $\mathrm{x}_{1}, \mathrm{x}_{2}$ & $\mathrm{y}$ & 11.33 & 18.67 & 37.67 & 96.67 \\
\hline 2 & $\varnothing$ & $\varnothing$ & - & - & - & - & 2 & $x_{2}$ & $\varnothing$ & 21.08 & 2.53 & 22.42 & 46.49 & 2 & $\mathrm{x}_{2}$ & $\varnothing$ & 16.83 & 18.67 & 20.83 & 96.67 \\
\hline & & & & & & & 3 & $\varnothing$ & $\varnothing$ & - & - & - & - & 3 & $\varnothing$ & $\varnothing$ & - & - & - & - \\
\hline \multicolumn{2}{|c|}{$\beta_{\mathrm{i}}^{\text {total }}$} & $\hat{\beta}_{\mathrm{k}}^{\mathrm{to}}$ & & 7.96 & 7.96 & 7.96 & \multicolumn{4}{|c|}{$\beta_{\mathrm{i}}^{\text {total }} \& \hat{\beta}_{\mathrm{k}}^{\text {total }}$} & 5.49 & 26.57 & 5.49 & \multicolumn{4}{|c|}{$\beta_{\mathrm{i}}^{\text {total }} \& \hat{\beta}_{\mathrm{k}}^{\text {total }}$} & 11.33 & 28.16 & 11.33 \\
\hline \multicolumn{4}{|c|}{$\eta_{0}$} & \multicolumn{3}{|c|}{0.384} & \multicolumn{4}{|c|}{$\eta_{0}$} & \multicolumn{3}{|c|}{0.238} & \multicolumn{4}{|c|}{$\eta_{0}$} & \multicolumn{3}{|c|}{0.217} \\
\hline
\end{tabular}

\begin{tabular}{|c|c|c|c|c|c|c|c|c|c|c|c|c|c|c|c|c|c|c|c|c|}
\hline \multicolumn{21}{|c|}{ DMU H } \\
\hline \multicolumn{7}{|c|}{$\mathrm{g}_{\mathrm{H}}=(1,5,1)$} & \multicolumn{7}{|c|}{$\mathrm{g}_{\mathrm{H}}=(5,1,1)$} & \multicolumn{7}{|c|}{$\mathrm{g}_{\mathrm{H}}=(1,1,5)$} \\
\hline $\mathrm{t}$ & $\mathrm{I}_{\mathrm{t}}^{-}$ & $\mathrm{O}_{\mathrm{t}}^{+}$ & $\beta_{\mathrm{t}}$ & $\mathrm{x}_{1}^{\mathrm{t}}$ & $x_{2}^{t}$ & $\mathrm{y}_{\mathrm{t}}$ & $\mathrm{t}$ & $\mathrm{I}_{\mathrm{t}}^{-}$ & $\mathrm{O}_{\mathrm{t}}^{+}$ & $\beta_{\mathrm{t}}$ & $\mathrm{x}_{1}^{\mathrm{t}}$ & $x_{2}^{t}$ & $\mathrm{y}_{\mathrm{t}}$ & $\mathrm{t}$ & $\mathrm{I}_{\mathrm{t}}^{-}$ & $\mathrm{O}_{\mathrm{t}}^{+}$ & $\beta_{\mathrm{t}}$ & $\mathrm{x}_{1}^{\mathrm{t}}$ & $x_{2}^{t}$ & $y_{t}$ \\
\hline 0 & $\mathrm{x}_{1}, \mathrm{x}_{2}$ & $\mathrm{y}$ & - & 40.00 & 45.00 & 30.00 & 0 & $\mathrm{x}_{1}, \mathrm{x}_{2}$ & $\mathrm{y}$ & - & 40.00 & 45.00 & 30.00 & 0 & $\mathrm{x}_{1}, \mathrm{x}_{2}$ & $\mathrm{y}$ & - & 40.00 & 45.00 & 30.00 \\
\hline 1 & $\mathrm{x}_{1}, \mathrm{x}_{2}$ & $\mathrm{y}$ & 7.34 & 32.66 & 8.28 & 37.34 & 1 & $\mathrm{x}_{1}, \mathrm{x}_{2}$ & $\mathrm{y}$ & 7.60 & 2.00 & 37.40 & 38.60 & 1 & $\mathrm{x}_{1}, \mathrm{x}_{2}$ & $\mathrm{y}$ & 13.60 & 26.40 & 31.40 & 98.00 \\
\hline 2 & $\mathrm{x}_{1}$ & $\varnothing$ & 14.84 & 17.81 & 8.28 & 37.34 & 2 & $\mathrm{x}_{2}$ & $\mathrm{y}$ & 5.40 & 2.00 & 32.00 & 43.00 & 2 & $x_{1}, x_{2}$ & $\mathrm{y}$ & 6.40 & 20.00 & 25.00 & 98.00 \\
\hline 3 & $\varnothing$ & $\varnothing$ & - & - & - & - & 3 & $x_{2}$ & $\varnothing$ & 10.00 & 2.00 & 22.00 & 43.00 & 3 & $\mathrm{x}_{2}$ & $\varnothing$ & 6.00 & 20.00 & 19 & 98.00 \\
\hline & & & & & & & 4 & $\varnothing$ & $\varnothing$ & - & - & - & - & 4 & $\varnothing$ & $\varnothing$ & - & - & - & - \\
\hline \multicolumn{2}{|c|}{$\beta_{i}^{\text {total }}$} & $\hat{\beta}_{\mathrm{k}}^{\text {to }}$ & & 22.18 & 7.34 & 7.34 & \multicolumn{4}{|c|}{$\beta_{\mathrm{i}}^{\text {total }} \& \hat{\beta}_{\mathrm{k}}^{\text {total }}$} & 7.60 & 23.00 & 13.00 & \multicolumn{4}{|c|}{$\beta_{\mathrm{i}}^{\text {total }} \& \hat{\beta}_{\mathrm{k}}^{\text {total }}$} & 20.00 & 26.00 & 13.60 \\
\hline \multicolumn{4}{|c|}{$\eta_{0}$} & \multicolumn{3}{|c|}{0.253} & \multicolumn{4}{|c|}{$\eta_{0}$} & \multicolumn{3}{|c|}{0.188} & \multicolumn{4}{|c|}{$\eta_{0}$} & \multicolumn{3}{|c|}{0.141} \\
\hline
\end{tabular}


Table 3. Results of lexicographic DDF projection of weak efficient DMUs I and J for three different directional vectors

\begin{tabular}{|c|c|c|c|c|c|c|c|c|c|c|c|c|c|c|c|c|c|c|c|c|}
\hline \multicolumn{21}{|c|}{ DMU I } \\
\hline \multicolumn{7}{|c|}{$\mathrm{g}_{\mathrm{H}}=(1,5,1)$} & \multicolumn{7}{|c|}{$\mathrm{g}_{\mathrm{H}}=(5,1,1)$} & \multicolumn{7}{|c|}{$\mathrm{g}_{\mathrm{H}}=(1,1,5)$} \\
\hline $\mathrm{t}$ & $\mathrm{I}_{\mathrm{t}}^{-}$ & $\mathrm{O}_{\mathrm{t}}^{+}$ & $\beta_{\mathrm{t}}$ & $\mathrm{x}_{1}^{\mathrm{t}}$ & $x_{2}^{t}$ & $y_{t}$ & $\mathrm{t}$ & $\mathrm{I}_{\mathrm{t}}^{-}$ & $\mathrm{O}_{\mathrm{t}}^{+}$ & $\beta_{\mathrm{t}}$ & $\mathrm{x}_{1}^{\mathrm{t}}$ & $x_{2}^{t}$ & $\mathrm{y}_{\mathrm{t}}$ & $\mathrm{t}$ & $\mathrm{I}_{\mathrm{t}}^{-}$ & $\mathrm{O}_{\mathrm{t}}^{+}$ & $\beta_{\mathrm{t}}$ & $x_{1}^{t}$ & $x_{2}^{t}$ & $y_{t}$ \\
\hline 0 & $\mathrm{x}_{1}, \mathrm{x}_{2}$ & $\mathrm{y}$ & - & 5.62 & 40.00 & 60.01 & 0 & $\mathrm{x}_{1}, \mathrm{x}_{2}$ & $\mathrm{y}$ & - & 5.62 & 40 & 60.01 & 0 & $\mathrm{x}_{1}, \mathrm{x}_{2}$ & $\mathrm{y}$ & - & 5.62 & 40.00 & 60.01 \\
\hline 1 & $\mathrm{x}_{2}$ & $\varnothing$ & 3.02 & - & 24.89 & - & 1 & $\mathrm{x}_{2}$ & $\varnothing$ & 15.11 & - & 24.89 & - & 1 & $\mathrm{x}_{2}$ & $\varnothing$ & 15.11 & - & 24.89 & - \\
\hline 2 & $\varnothing$ & $\varnothing$ & - & - & - & - & 2 & $\varnothing$ & $\varnothing$ & - & - & - & - & 2 & $\varnothing$ & $\varnothing$ & - & - & - & - \\
\hline \multicolumn{2}{|c|}{$\beta_{\mathrm{i}}^{\text {total }}$} & $\hat{\beta}_{\mathrm{k}}^{\mathrm{to}}$ & & 0.00 & 3.02 & 0.00 & & $i^{\text {total }} \&$ & $\hat{\beta}_{\mathrm{k}}^{\mathrm{tot}}$ & & - & 15.11 & - & & $3_{i}^{\text {total }}$ & $\hat{\beta}_{\mathrm{k}}^{\mathrm{tot}}$ & & 0.00 & 15.11 & 0.00 \\
\hline \multicolumn{4}{|c|}{$\eta_{0}$} & \multicolumn{3}{|c|}{0.811} & \multicolumn{4}{|c|}{$\eta_{0}$} & \multicolumn{3}{|c|}{0.811} & \multicolumn{4}{|c|}{$\eta_{0}$} & \multicolumn{3}{|c|}{0.811} \\
\hline
\end{tabular}

\begin{tabular}{|c|c|c|c|c|c|c|c|c|c|c|c|c|c|c|c|c|c|c|c|c|}
\hline \multicolumn{21}{|c|}{ DMU J } \\
\hline \multicolumn{7}{|c|}{$\mathrm{g}_{\mathrm{J}}=(1,5,1)$} & \multicolumn{7}{|c|}{$\mathrm{g}_{\mathrm{J}}=(5,1,1)$} & \multicolumn{7}{|c|}{$\mathrm{g}_{\mathrm{J}}=(1,1,5)$} \\
\hline $\mathrm{t}$ & $\mathrm{I}_{\mathrm{t}}^{-}$ & $\mathrm{O}_{\mathrm{t}}^{+}$ & $\beta_{\mathrm{t}}$ & $\mathrm{x}_{1}^{\mathrm{t}}$ & $\mathrm{x}_{2}^{\mathrm{t}}$ & $\mathrm{y}_{\mathrm{t}}$ & $\mathrm{t}$ & $\mathrm{I}_{\mathrm{t}}^{-}$ & $\mathrm{O}_{\mathrm{t}}^{+}$ & $\beta_{\mathrm{t}}$ & $\mathrm{x}_{1}^{\mathrm{t}}$ & $\mathrm{x}_{2}^{\mathrm{t}}$ & $\mathrm{y}_{\mathrm{t}}$ & $\mathrm{t}$ & $\mathrm{I}_{\mathrm{t}}^{-}$ & $\mathrm{O}_{\mathrm{t}}^{+}$ & $\beta_{\mathrm{t}}$ & $\mathrm{x}_{1}^{\mathrm{t}}$ & $\mathrm{x}_{2}^{\mathrm{t}}$ & $\mathrm{y}_{\mathrm{t}}$ \\
\hline 0 & $\mathrm{x}_{1}, \mathrm{x}_{2}$ & $\mathrm{y}$ & - & 2.00 & 35.00 & 22.00 & 0 & $\mathrm{x}_{1}, \mathrm{x}_{2}$ & $\mathrm{y}$ & - & 2.00 & 35.00 & 22.00 & 0 & $\mathrm{x}_{1}, \mathrm{x}_{2}$ & $\mathrm{y}$ & - & 2.00 & 35.00 & 22.00 \\
\hline 1 & $\mathrm{x}_{2}$ & $\mathrm{y}$ & 2.60 & 2.00 & 22.00 & 24.60 & 1 & $\mathrm{x}_{2}$ & $\mathrm{y}$ & 13.00 & 2.00 & 22.00 & 35.00 & 1 & $\mathrm{x}_{2}$ & $\mathrm{y}$ & 4.20 & 2.00 & 30.80 & 43.00 \\
\hline 2 & $\varnothing$ & $\mathrm{y}$ & 18.40 & 2.00 & 22.00 & 43.00 & 2 & $\varnothing$ & $\mathrm{y}$ & 8.00 & 2.00 & 22.00 & 43.00 & 2 & $\mathrm{x}_{2}$ & $\varnothing$ & 8.80 & 2.00 & 22.00 & 43.00 \\
\hline 3 & $\varnothing$ & $\varnothing$ & - & - & - & - & 3 & $\varnothing$ & $\varnothing$ & - & - & - & - & 3 & $\varnothing$ & $\varnothing$ & - & - & - & - \\
\hline \multicolumn{4}{|c|}{$\beta_{\mathrm{i}}^{\text {total }} \& \hat{\beta}_{\mathrm{k}}^{\text {total }}$} & 0.00 & 2.60 & 21.00 & \multicolumn{4}{|c|}{$\beta_{\mathrm{i}}^{\text {total }} \& \hat{\beta}_{\mathrm{k}}^{\text {total }}$} & 0.00 & 13.00 & 21.00 & \multicolumn{4}{|c|}{$\beta_{\mathrm{i}}^{\text {total }} \& \hat{\beta}_{\mathrm{k}}^{\text {total }}$} & 0.00 & 13.00 & 4.20 \\
\hline \multicolumn{4}{|c|}{$\eta_{0}$} & \multicolumn{3}{|c|}{0.417} & \multicolumn{4}{|c|}{$\eta_{0}$} & \multicolumn{3}{|c|}{0.417} & \multicolumn{4}{|c|}{$\eta_{0}$} & \multicolumn{3}{|c|}{0.417} \\
\hline
\end{tabular}


Table 4. Results of smallest improvement DDF model (29)

\begin{tabular}{|c|c|c|c|c|c|c|c|c|c|c|c|c|}
\hline A & 0 & 0 & 0 & 0 & 57.8075 & 6.6849 & 35.5075 & 2301.4393 & 12 & 30 & 90 & $0.00: 23.062$ \\
\hline B & 0 & 0 & 0 & 0 & 17.5881 & 69.4968 & 12.9151 & -406.5041 & 25 & 9 & 51 & 0.00:01.805 \\
\hline $\mathrm{C}$ & 0 & 0 & 0 & 0 & 6.1466 & 78.4589 & 15.3945 & -49.7373 & 43 & 11 & 70 & 0.00:00.385 \\
\hline $\mathrm{E}$ & 0 & 0 & 0 & 0 & 74.8235 & 15.3998 & 9.7767 & -68.0462 & 2 & 22 & 43 & 0.00:00.289 \\
\hline $\mathrm{F}$ & 0 & 0 & 0 & 0 & 42.5249 & 53.3085 & 4.1666 & -531.6178 & 5 & 7 & 13 & 0.00:00.401 \\
\hline $\mathrm{G}$ & 51.3684 & 10.7895 & 40.5789 & 0 & 15.2919 & 72.8267 & 11.8814 & -431.7891 & 19.2105 & 8.4211 & 40 & $0.00: 03.852$ \\
\hline $\mathrm{J}$ & 34 & 0 & 13 & 21 & 76.3393 & 16.4081 & 7.2526 & -201.7968 & 2 & 22 & 43 & 0.00:00.604 \\
\hline
\end{tabular}


Table 5. Results of smallest improvement DDF model (30)

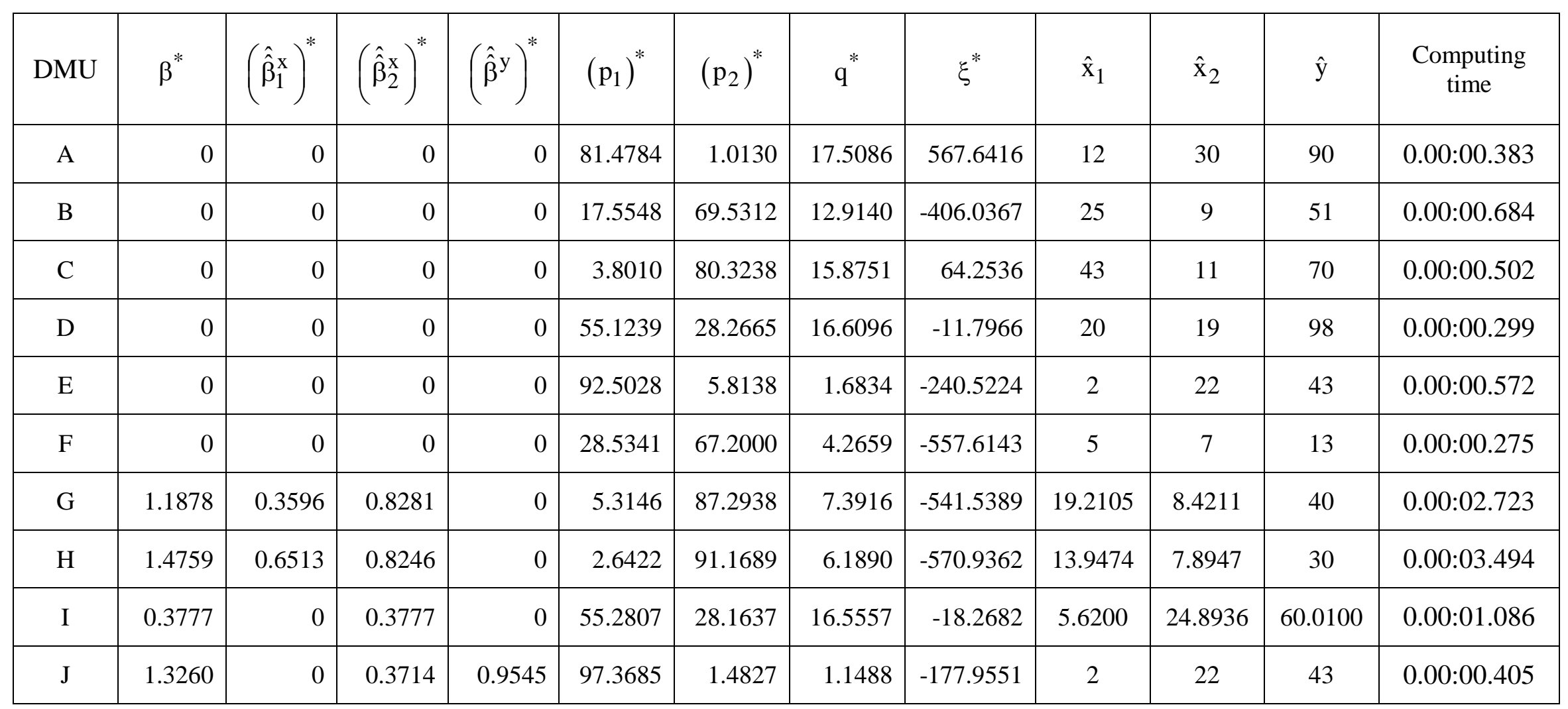


Table 6. Results of largest improvement DDF models (15) and (18)

\begin{tabular}{|c|c|c|c|c|c|c|c|c|c|c|c|c|c|c|}
\hline & \multicolumn{7}{|c|}{ Model (15) } & \multicolumn{7}{|c|}{ Model (18) } \\
\hline DMU & $\beta^{*}$ & $\left(\hat{\beta}_{1}^{\mathrm{x}}\right)^{*}$ & $\left(\hat{\beta}_{2}^{\mathrm{X}}\right)^{*}$ & $\left(\hat{\beta}^{y}\right)^{*}$ & $\hat{\mathrm{x}}_{1}$ & $\hat{\mathrm{x}}_{2}$ & $\hat{y}$ & $\beta^{*}$ & $\left(\hat{\hat{\beta}}_{1}^{\mathrm{x}}\right)^{*}$ & $\left(\hat{\hat{\beta}}_{2}^{\mathrm{x}}\right)^{*}$ & $\left(\hat{\hat{\beta}}^{\mathrm{y}}\right)^{*}$ & $\hat{\mathrm{x}}_{1}$ & $\hat{\mathrm{x}}_{2}$ & $\hat{y}$ \\
\hline A & 0 & 0 & 0 & 0 & 12 & 30 & 90 & 0 & 0 & 0 & 0 & 12 & 30 & 90 \\
\hline B & 0 & 0 & 0 & 0 & 25 & 9 & 51 & 0 & 0 & 0 & 0 & 25 & 9 & 51 \\
\hline $\mathrm{C}$ & 0 & 0 & 0 & 0 & 43 & 11 & 70 & 0 & 0 & 0 & 0 & 43 & 11 & 70 \\
\hline $\mathrm{D}$ & 0 & 0 & 0 & 0 & 20 & 19 & 98 & 0 & 0 & 0 & 0 & 20 & 19 & 98 \\
\hline $\mathrm{E}$ & 0 & 0 & 0 & 0 & 2 & 22 & 43 & 0 & 0 & 0 & 0 & 2 & 22 & 43 \\
\hline $\mathrm{F}$ & 0 & 0 & 0 & 0 & 5 & 7 & 13 & 0 & 0 & 0 & 0 & 5 & 7 & 13 \\
\hline $\mathrm{G}$ & 98 & 10 & 30 & 58 & 20 & 19 & 98 & 2.3956 & 0.3333 & 0.6122 & 1.4500 & 20 & 19 & 98 \\
\hline $\mathrm{H}$ & 114 & 20 & 26 & 68 & 20 & 19 & 98 & 3.3444 & 0.5000 & 0.5778 & 2.2667 & 20 & 19 & 98 \\
\hline I & 15.108 & 0.000 & 15.104 & 0.004 & 5.620 & 24.896 & 60.014 & 0.3778 & 0.0002 & 0.3776 & 0 & 5.6191 & 24.8953 & 60.0100 \\
\hline $\mathrm{J}$ & 34 & 0 & 13 & 21 & 2 & 22 & 43 & 1.3260 & 0 & 0.3714 & 0.9545 & 2 & 22 & 43 \\
\hline
\end{tabular}


Figure 1. Lexicographic DDF projection of inefficient DMUs G and $\mathrm{H}$ for three different directional vectors (the coordinates of the points are shown with one decimal digit; the exact values are shown in Table 2)

$\mathrm{DMU}_{G}=(30,49,40), \mathrm{g}_{G}=(1,5,1), \mathrm{T}=1$

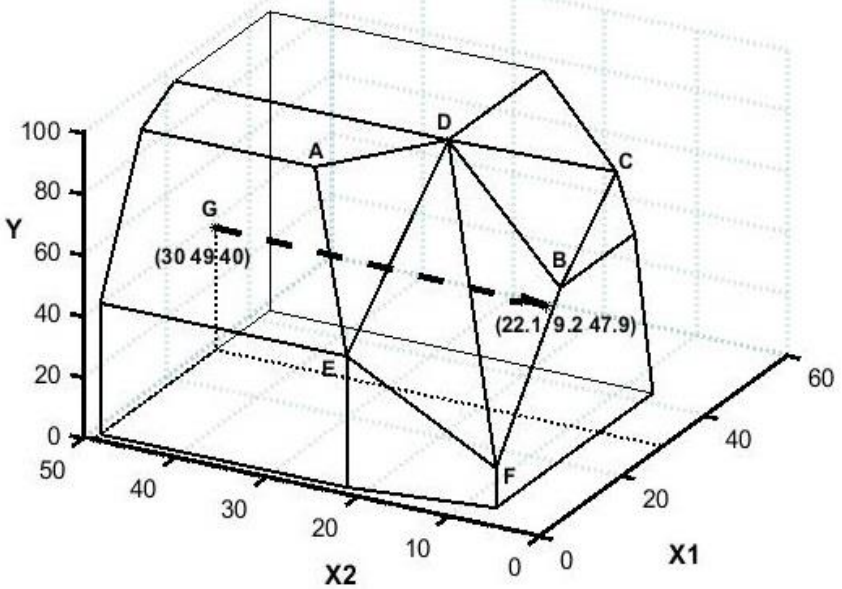

$\mathrm{DMU}_{\mathrm{H}}=(40,45,30), \mathrm{g}_{\mathrm{H}}=(1,5,1), \mathrm{T}=2$

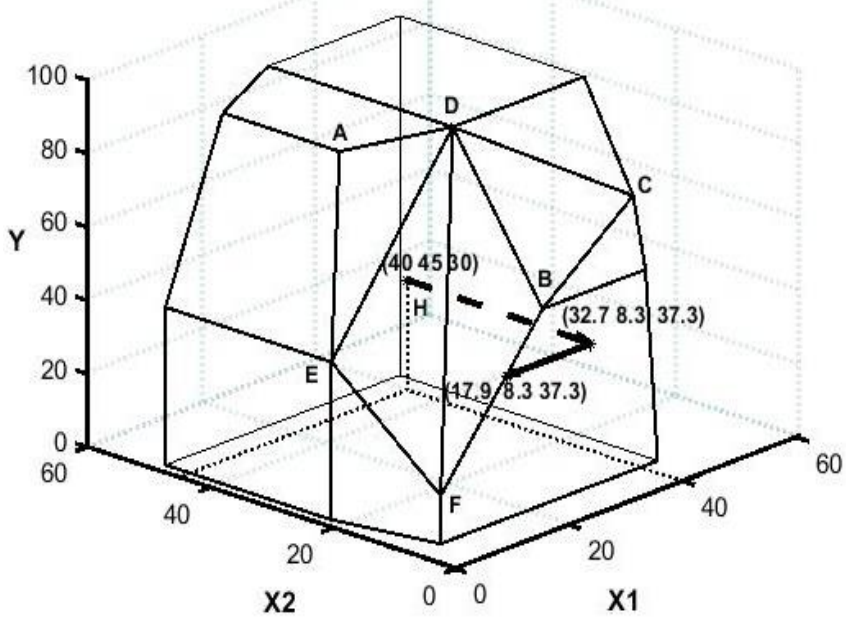

$\mathrm{DMU}_{\mathrm{G}}=(30,49,40), \mathrm{g}_{\mathrm{G}}=(5,1,1), \mathrm{T}=2$

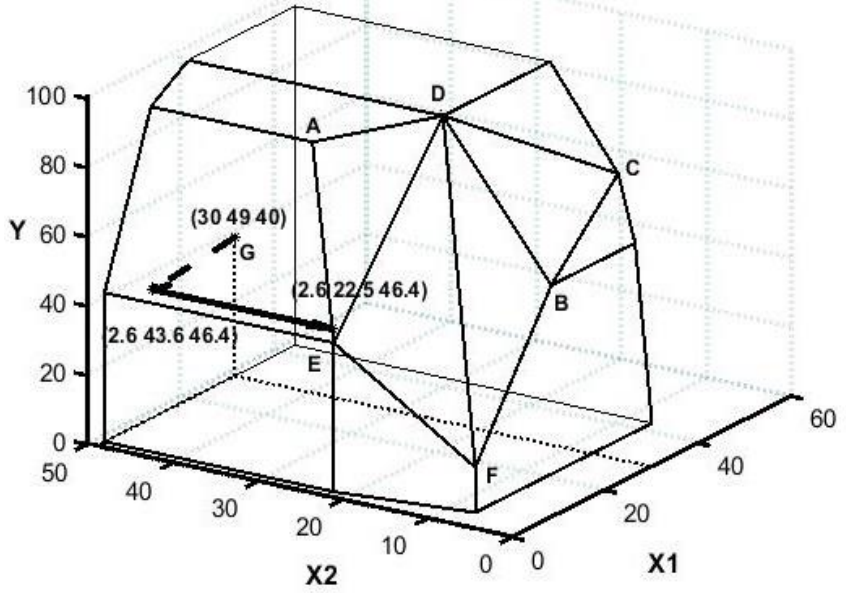

$\mathrm{DMU}_{\mathrm{H}}=(40,45,30), \mathrm{g}_{\mathrm{H}}=(5,1,1), \mathrm{T}=3$

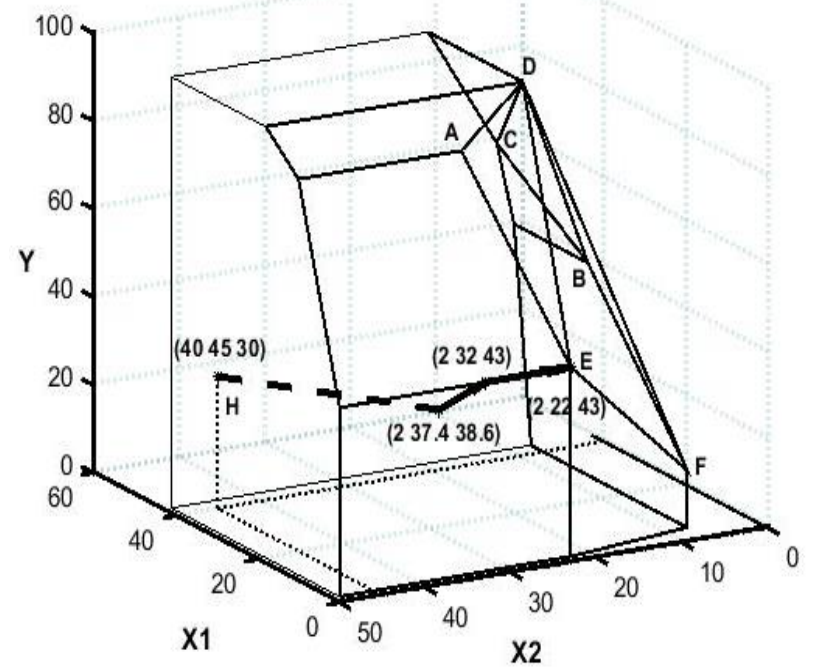

$\mathrm{DMU}_{\mathrm{G}}=(30,49,40), \mathrm{g}_{\mathrm{G}}=(1,1,5), \mathrm{T}=2$
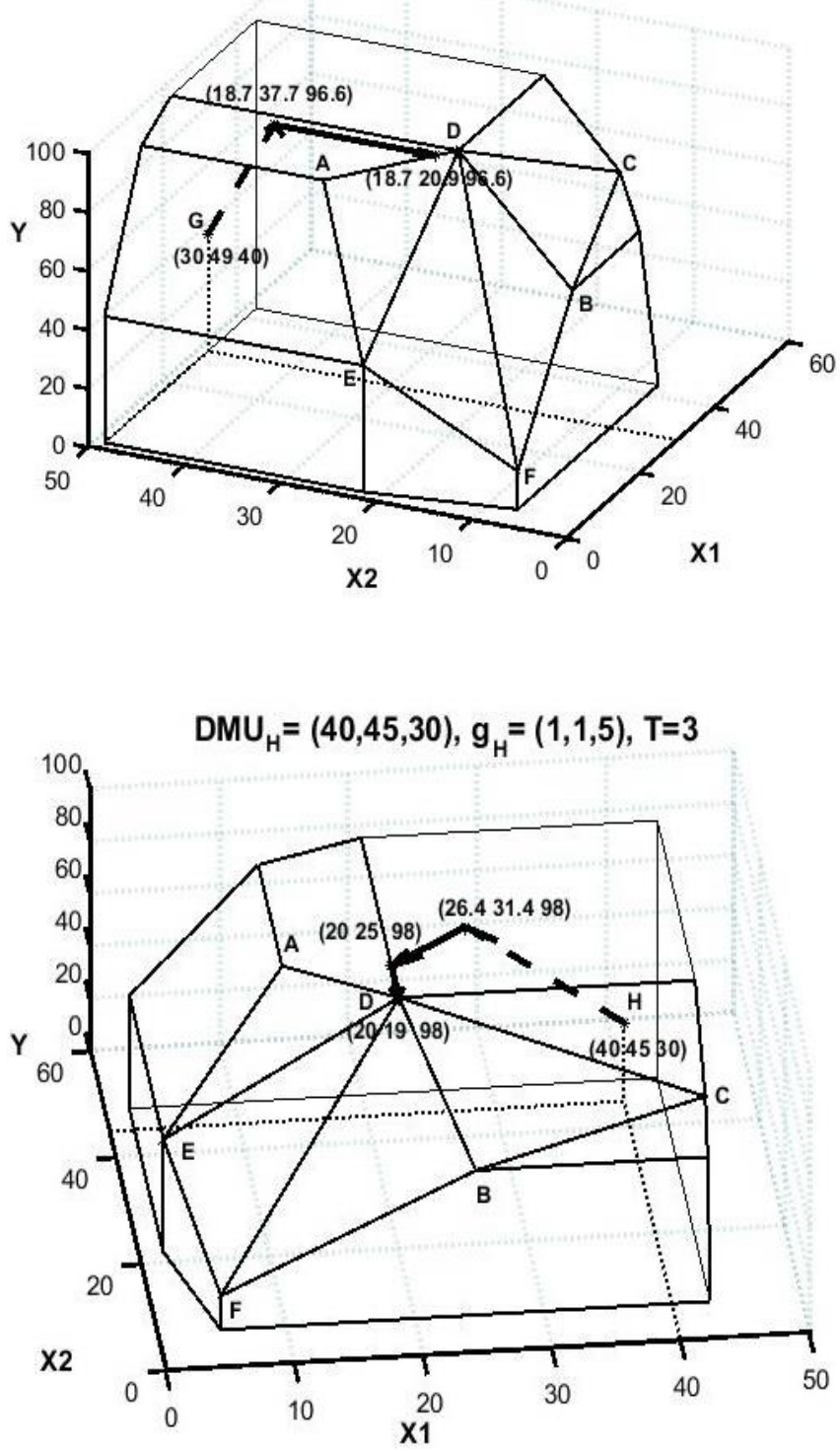
Figure 2. Lexicographic DDF projection of weak efficient DMUs I and J for three different directional vectors (the coordinates of the points are shown with one decimal digit; the exact values are shown in Table 3)

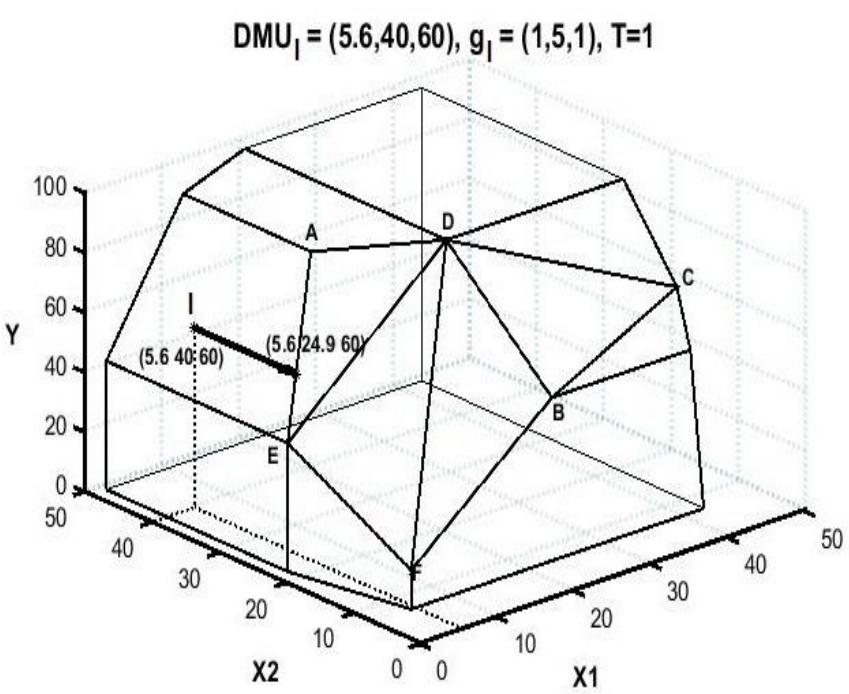

$\operatorname{DMU}_{\mathrm{J}}=(2,35,22), g_{\mathrm{J}}=(1,5,1), \mathrm{T}=2$

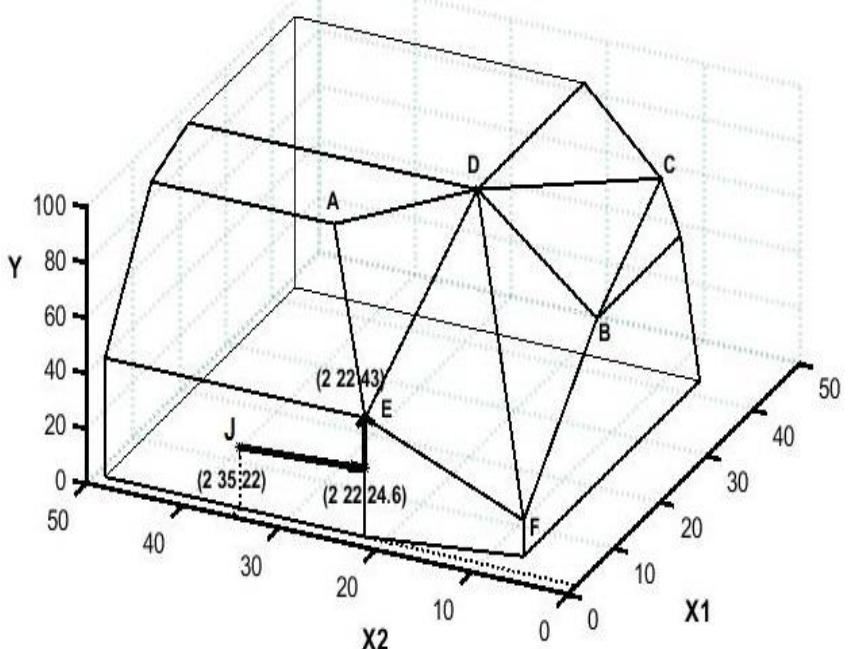

$\mathrm{DMU}_{1}=(5.6,40,60), g_{1}=(5,1,1), \mathrm{T}=1$

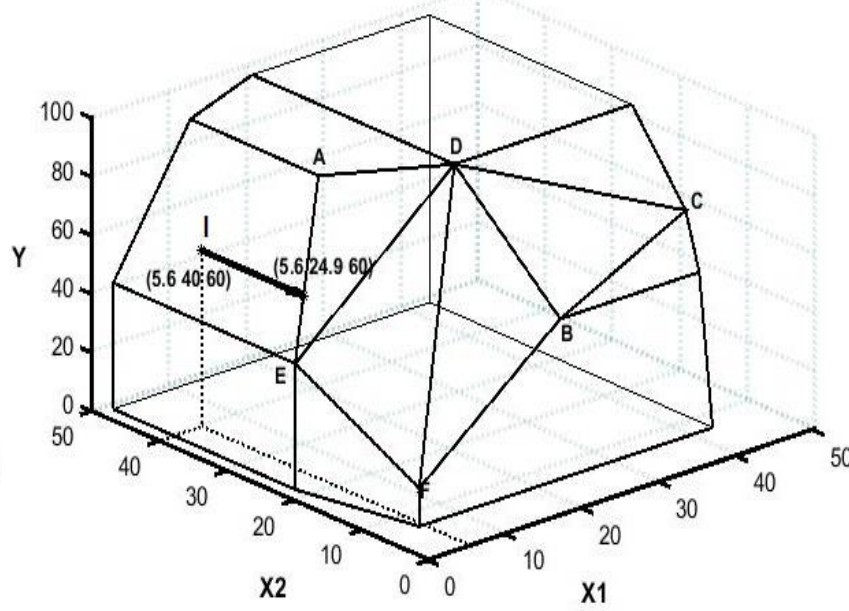

$\mathrm{DMU}_{\mathrm{J}}=(2,35,22), \mathrm{g}_{\mathrm{J}}=(5,1,1), \mathrm{T}=2$

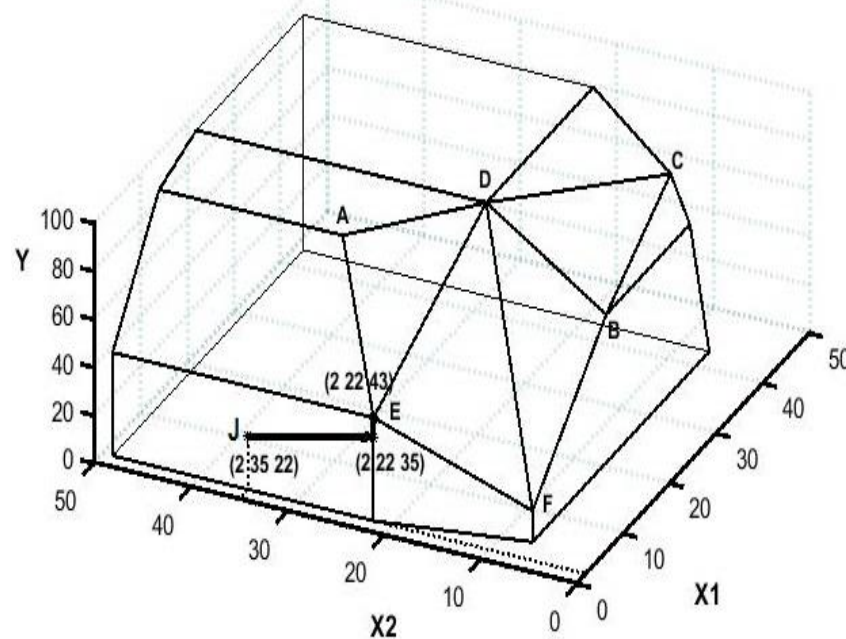

$\mathrm{DMU}_{\mid}=(5.6,40,60), g_{1}=(1,1,5), \mathrm{T}=1$

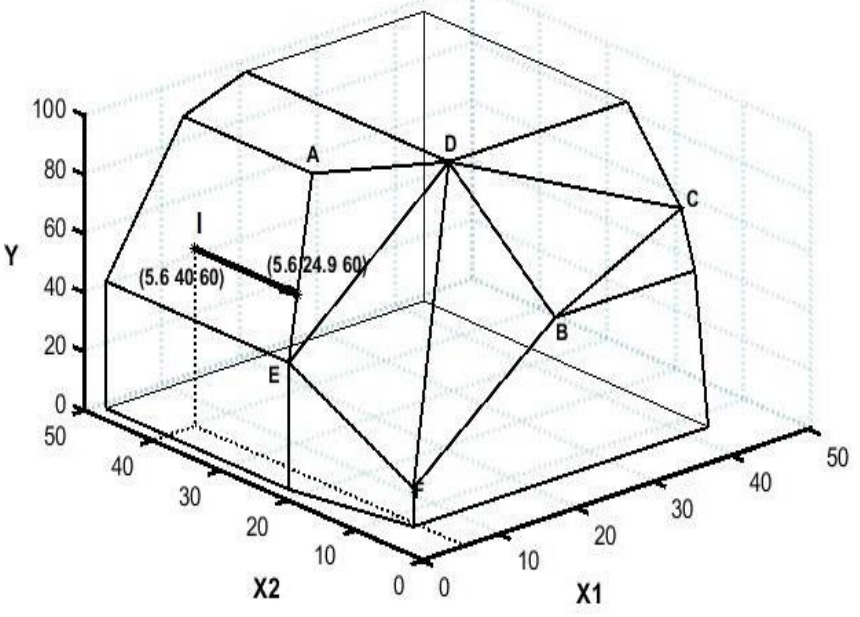

$\operatorname{DMU}_{\mathrm{J}}=(2,35,22), \mathrm{g}_{\mathrm{J}}=(1,1,5), \mathrm{T}=2$

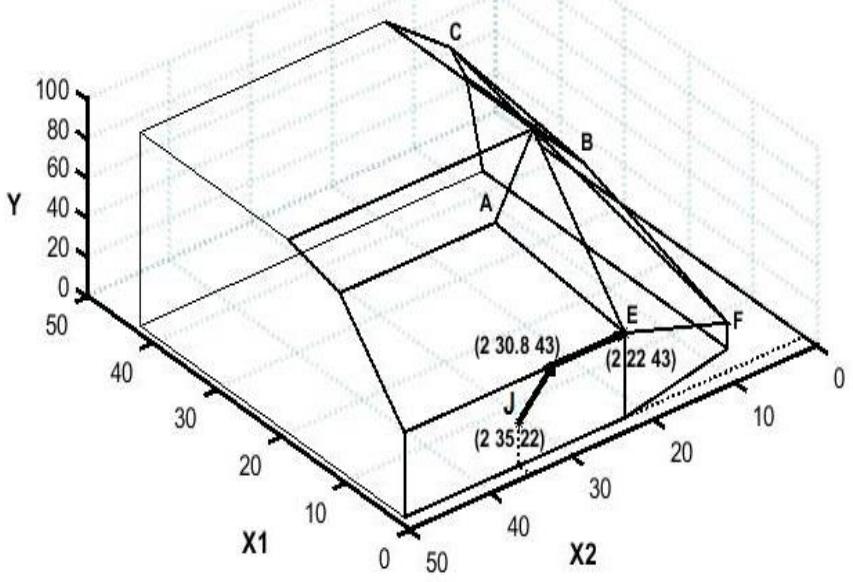


Figure 3. Largest and smallest improvement projections of inefficient DMUs

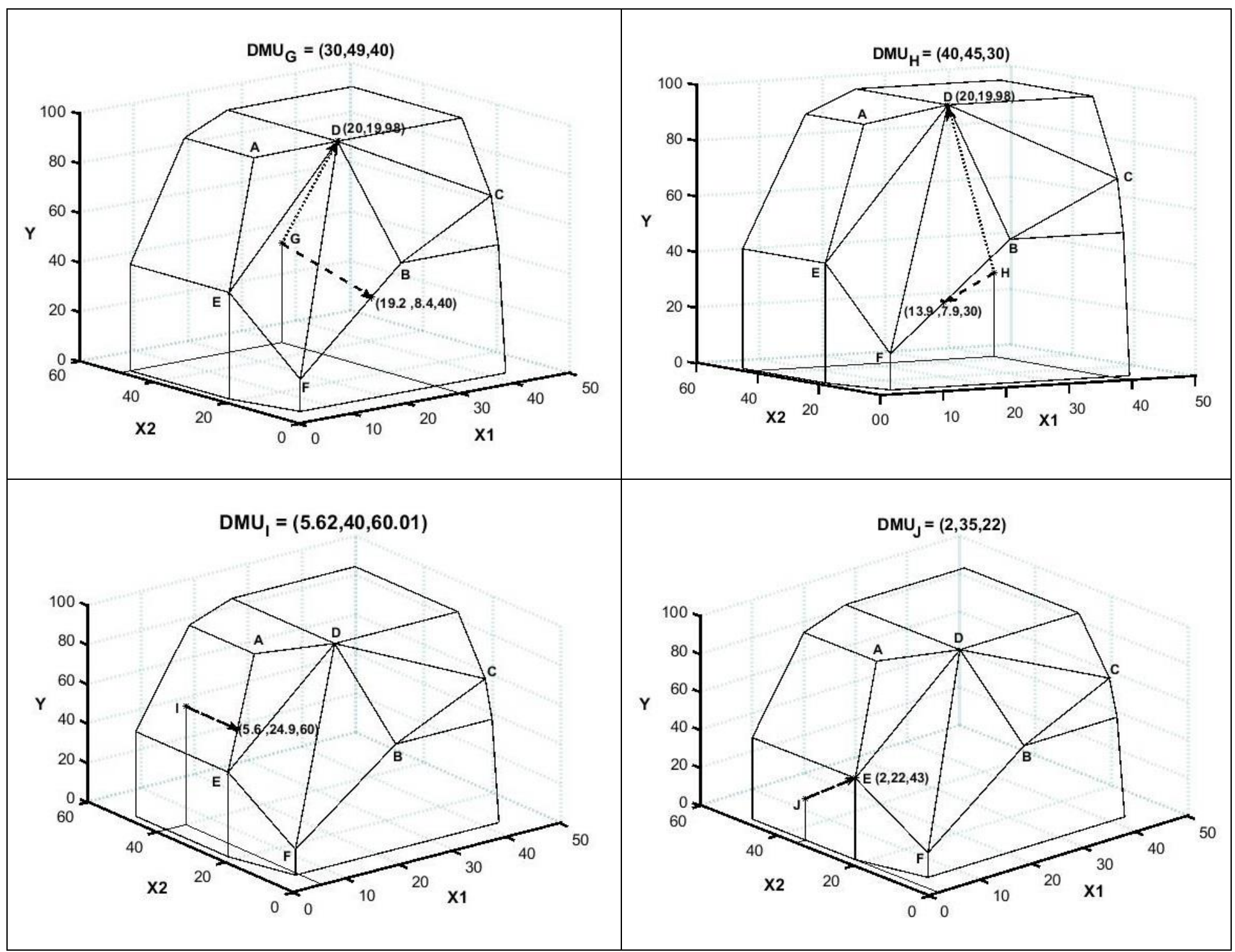

Note: Smallest improvement $----\longrightarrow \quad$ Largest improvement 
Figure 4. Flowchart of the lexicographic radial approaches of Korhonen et al. (2018) and Coelli (1998)

Korhonen et al. (2018)

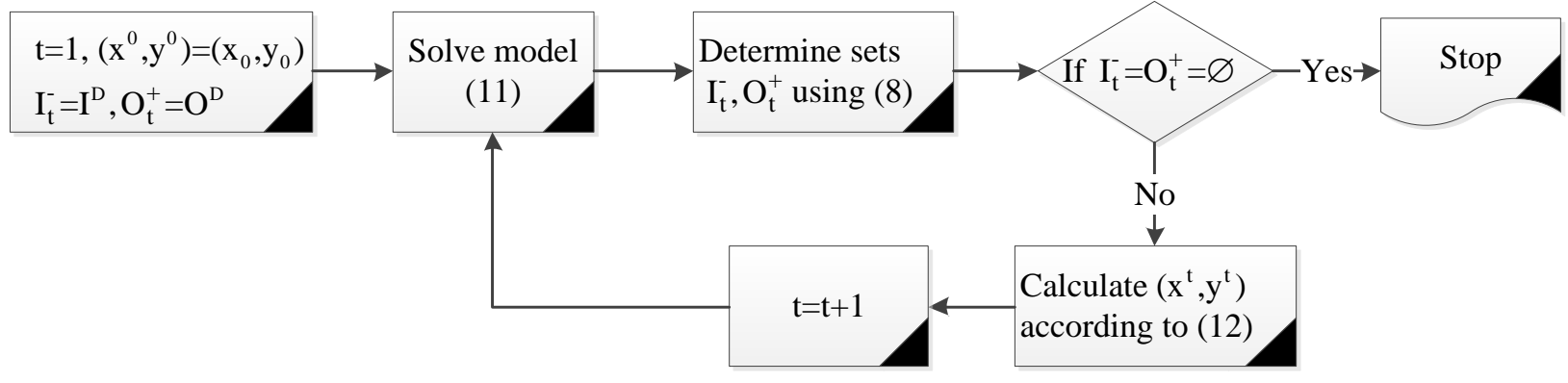

Coelli (1998)

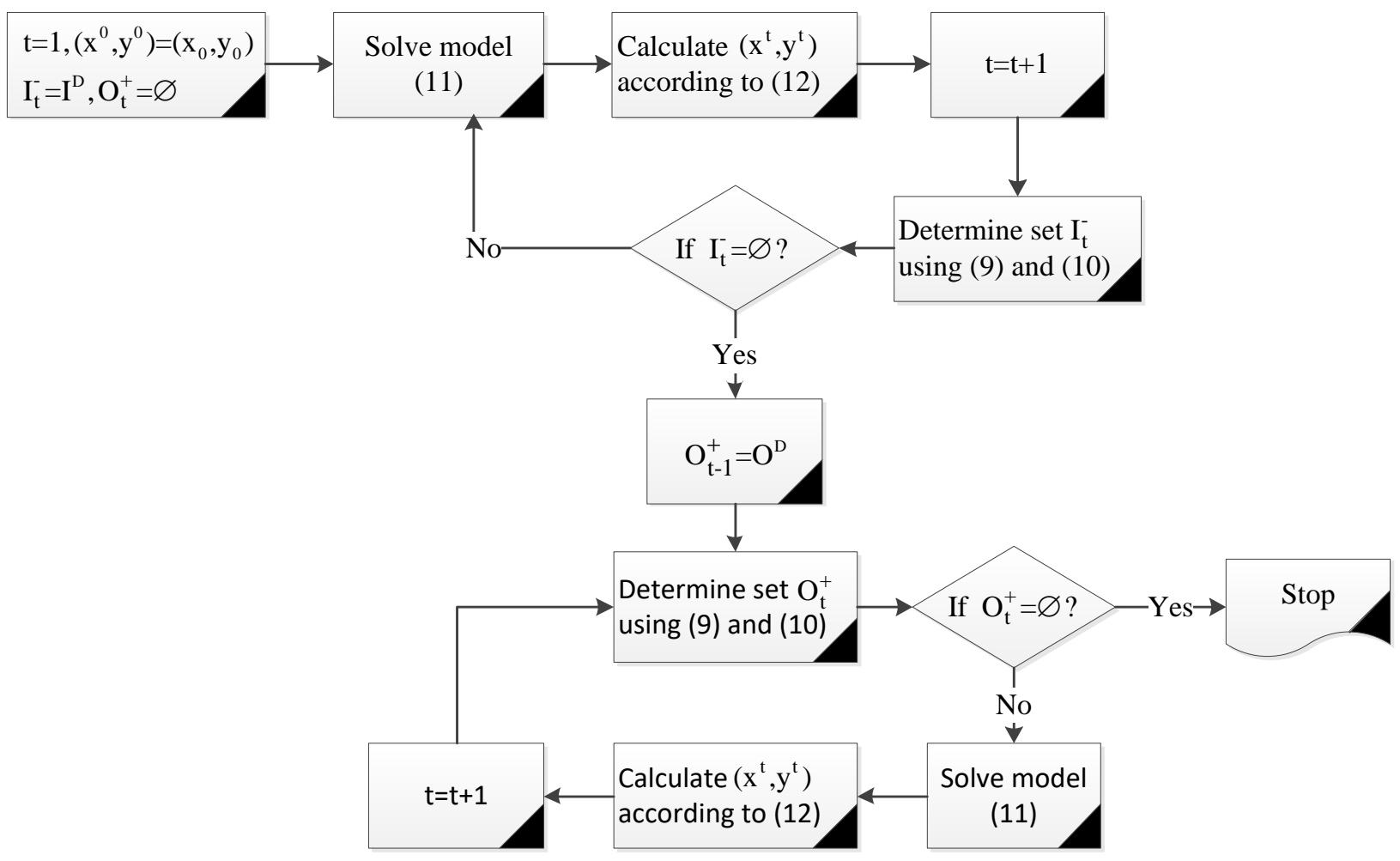


Figure 5. Flowchart of the proposed lexicographic DDF approach

Lexicographic DDF approach

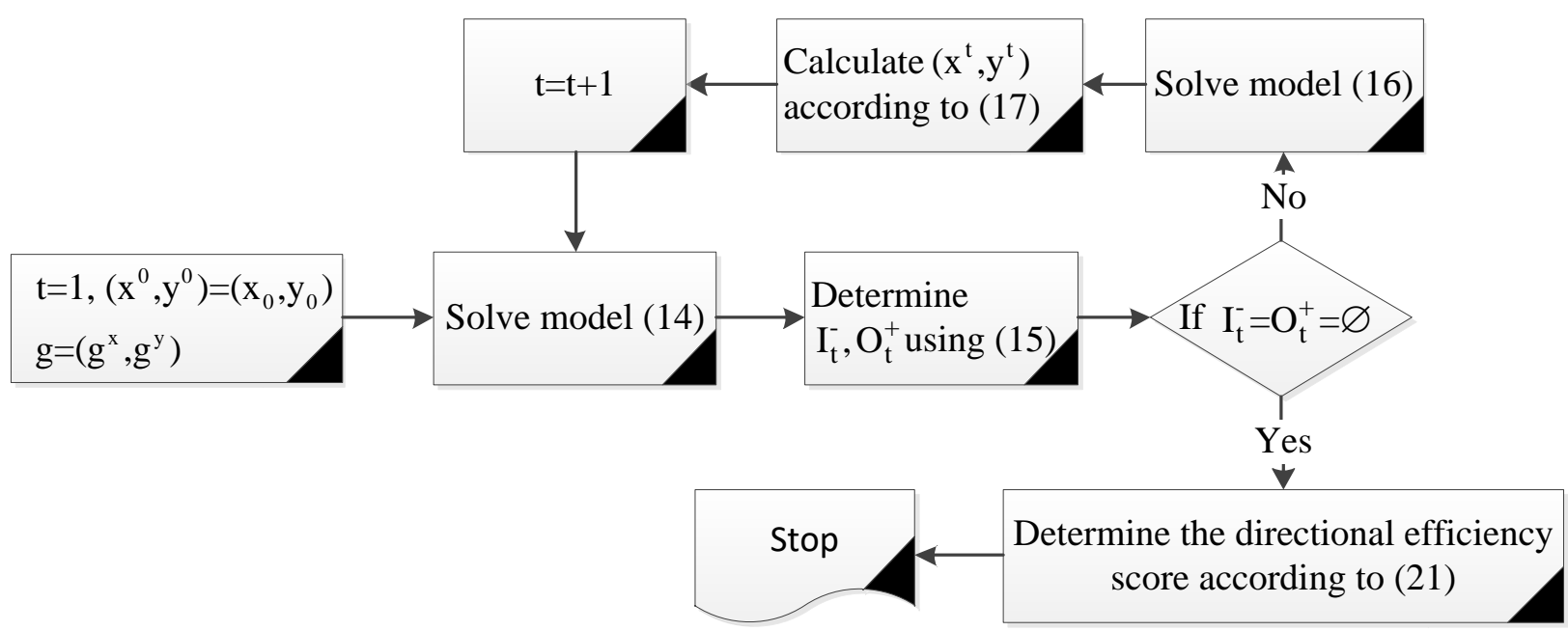

